University of Louisville

ThinkIR: The University of Louisville's Institutional Repository

Electronic Theses and Dissertations

8-2014

\title{
Building a metabolic bridge between glycolysis and sphingolipid biosynthesis : implications in cancer.
}

Morgan L. Stathem

University of Louisville

Follow this and additional works at: https://ir.library.louisville.edu/etd

Part of the Pharmacy and Pharmaceutical Sciences Commons

\section{Recommended Citation}

Stathem, Morgan L., "Building a metabolic bridge between glycolysis and sphingolipid biosynthesis : implications in cancer." (2014). Electronic Theses and Dissertations. Paper 1374.

https://doi.org/10.18297/etd/1374

This Master's Thesis is brought to you for free and open access by ThinkIR: The University of Louisville's Institutional Repository. It has been accepted for inclusion in Electronic Theses and Dissertations by an authorized administrator of ThinkIR: The University of Louisville's Institutional Repository. This title appears here courtesy of the author, who has retained all other copyrights. For more information, please contact thinkir@louisville.edu. 
BUILDING A METABOLIC BRIDGE BETWEEN GLYCOLYSIS AND SPHINGOLIPID BIOSYNTHESIS: IMPLICATIONS IN CANCER

\author{
By \\ Morgan L. Stathem \\ B.S., University of Georgia, 2010
}

\begin{abstract}
A Thesis
Submitted to the Faculty of the School of Medicine of the University of Louisville In Partial Fulfillment of the Requirements for the Degree of

Master of Science

Department of Pharmacology and Toxicology University of Louisville

Louisville, KY
\end{abstract}

August 2014 

BUILDING A METABOLIC BRIDGE BETWEEN GLYCOLYSIS AND SPHINGOLIPID BIOSYNTHESIS: IMPLICATIONS IN CANCER

\author{
By \\ Morgan L. Stathem \\ B.S., University of Georgia, 2010
}

Thesis Approved on

$08 / 07 / 2014$

by the following Thesis Committee:

Leah Siskind, Ph.D.

Levi Beverly, Ph.D.

Geoff Clark, Ph.D.

Brian Clem, Ph.D. 


\section{DEDICATION}

I dedicate this work to my Mother. You are the constant inspiration in all of my work. I am who I am because of you. I owe all of my successes to your tireless pursuit of happiness for your children, no matter what the cost. I promise you I will work just as tirelessly, so that one day no mother will ever have to be faced with the hard road that cancer has laid out for you. I love you, Mom. 


\section{ACKNOWLEDGEMENTS}

I would like to extend my sincerest gratitude to my mentor, Dr. Leah Siskind, for all of her patience, guidance and understanding. You are a true model of what a mentor should be. Thanks for making sphingolipids cool, a feat not to be underestimated. I would also like to extend the same gratitude to my co-mentor Dr. Levi Beverly, for taking me under his wing when I moved to Louisville and for sharing his knowledge and love of cancer research with me. To the other members of my committee, Dr. Brian Clem and Dr. Geoffrey Clark, I thank you for your valuable input to this work. 


\title{
ABSTRACT \\ BUILDING A METABOLIC BRIDGE BETWEEN GLYCOLYSIS AND SPHINGOLIPID BIOSYNTHESIS: IMPLICATIONS IN CANCER
}

\author{
Morgan L. Stathem
}

$08 / 07 / 2014$

Cancer therapeutics has seen an emergence and re-emergence of two metabolic fields in recent years, namely bioactive sphingolipids and glycolytic metabolism. Anaerobic glycolysis and its role in cancer has been recognized in cancer biology over 90 years. In recent decades, the role of sphingolipids in cancer cell metabolism has gained recognition, notably ceramide's essential role in programmed cell death and the role of the glucosylceramide synthase (GCS) in chemotherapeutic resistance. Despite this knowledge, a direct link between these two fields has yet to be concretely drawn. Herein, we show that in a model of highly glycolytic cells, generation of the glycosphingolipid (GSL) glucosylceramide (GlcCer) by GCS was elevated in response to increased glucose availability, while glucose deprivation diminished GSL levels. This effect was likely substrate dependent, independent of both GCS levels and activity. Conversely, leukemia cells with elevated GSLs showed a significant change in GCS activity, but no change in glucose uptake or GCS expression. In a leukemia cell line with elevated GlcCer, treatment with inhibitors of glycolysis or the pentose phosphate pathway significantly decreased GlcCer levels. When combined with pre-clinical inhibitor ABT-263, this effect was augmented and production of proapoptotic sphingolipid ceramide increased. Taken together, we have shown that there exists a definitive link between glucose metabolism and GSL production, laying the groundwork for connecting two distinct yet essential metabolic fields in cancer research. Furthermore, we have 
proposed a novel combination therapeutic option targeting two metabolic vulnerabilities for the treatment of leukemia. 


\section{TABLE OF CONTENTS}

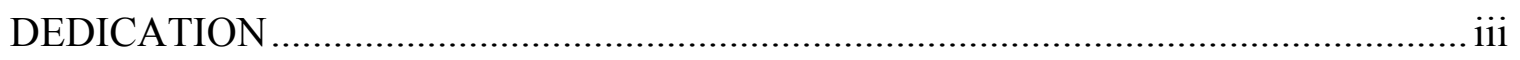

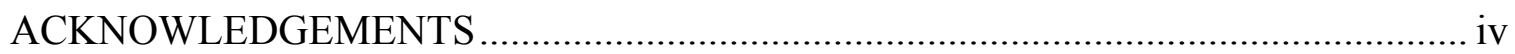

ABSTRACT

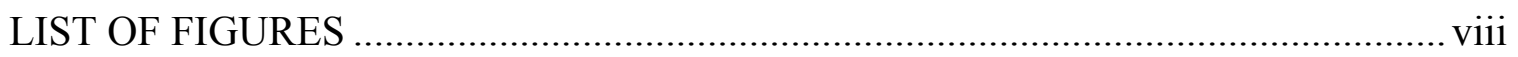

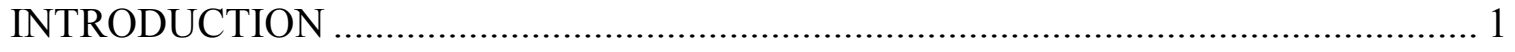

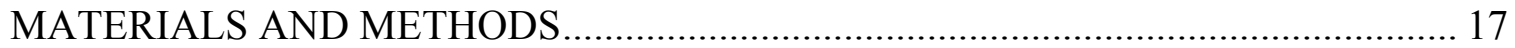

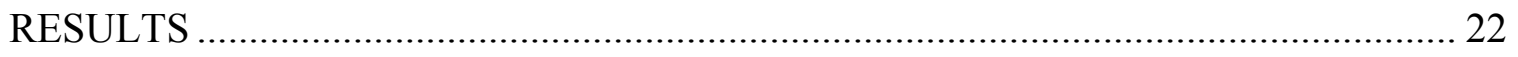

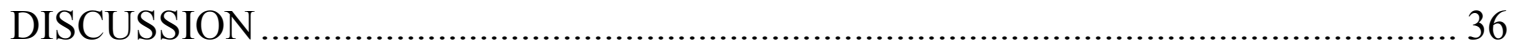

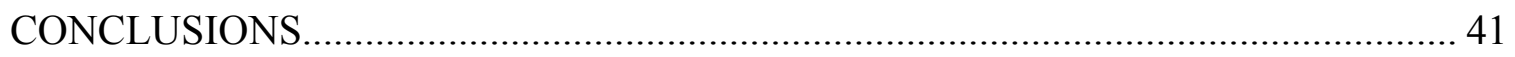

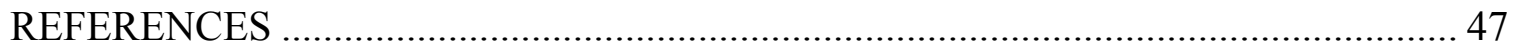

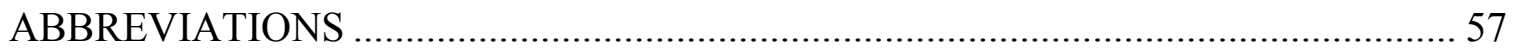

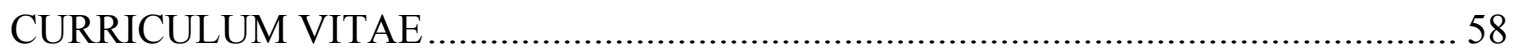




\section{LIST OF FIGURES}

FIGURE PAGE

Figure 1: An overview of sphingolipid metabolism. .............................................. 16

Figure 2: FL5.12 cells overexpressing GLUT1 and HK1 are highly glycolytic. ............ 28

Figure 3: Glucosylceramide levels are elevated in a model of highly glycolytic cells..... 29

Figure 4: Inhibition of FL5.12 cells with metabolic inhibitors depletes GSLs. .............. 30

Figure 5: GlcCer levels differ among a panel of leukemia cell lines............................ 31

Figure 6: GCS activity is increased in leukemia cell lines with elevated GSLs.............. 32

Figure 7: Preincubation with GCS Inhibitors confers resistance to doxorubicin in

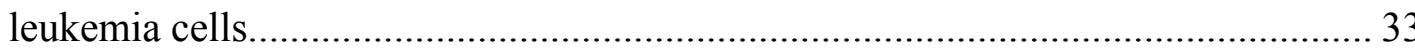

Figure 8: Inhibitors of glycolytic metabolism and the pentose phosphate pathway synergize with an inhibitor of anti-apoptic BCL2 proteins. 34

Figure 9: Inhibitors of glycolytic metabolism and the pentose phosphate pathway synergize with an inhibitor of anti-apoptotic BCL2 proteins to increase ceramide:glycosphingolipid ratios.

Figure 10: Proposed mechanism of glycosphingolipid production via formation of substrates via glycolysis, the PPP and glycogenesis in highly glycolytic cells. 40 


\section{INTRODUCTION}

Sneaky, smart, conniving, stubborn. Evasive and yet ever-present. Our knowledge of "the emperor of all maladies" [1] has never run deeper, yet despite profound advances in its detection and treatment, most standard of care regiments are subject to grueling side effects at best, eventual resistance at worst. In its quest for novel treatment targets, cancer therapeutics has come full circle to revisit a metabolic hallmark of cancer cells first brought to light by Otto Warburg over 80 years ago, that of aerobic glycolysis. While revolutionary at the time, it is now recognized that this aberration is only a small piece of the puzzle of deregulated cancer cell metabolism. More recently, it has been shown that tumor cells present with altered sphingolipid profiles at baseline, in correlation with increasing aggressiveness and in response to chemotherapeutics. Despite these two seemingly unrelated facets of metabolism, it is understood that no metabolic alteration in cancer stands as an island unto itself, and we present data to show that the areas of glycolytic and sphingolipid metabolism are no exception to this rule.

\section{Alterations in Cellular and Systemic Glucose Metabolism in Cancer}

The role of aerobic glycolysis in cancer has been extensively reviewed by experts in the field of cancer metabolism [2-8]. To attempt to summarize this work would not give justice to the wealth of knowledge that exists, however a succinct overview of glycolytic metabolism in relation to the current topic will be presented here.

In "normal" (differentiated, non-replicating) cells under normoxic conditions, the majority of the cell's energy demands are generated through oxidative phosphorylation in the mitochondria, using reducing equivalents such as $\mathrm{NADH}$ and succinate generated through upstream catabolic 
pathways such as glycolysis, beta oxidation and the tricarboxylic acid (TCA) cycle to form ATP. Only under conditions where oxygen is limiting do these cells revert to glycolytic metabolism for ATP production and subsequently produce excess amounts of lactate. On the other hand, transformed cells do not follow the same rules of metabolism. The Warburg Effect states that cancer cells take up increased amounts of glucose compared to their non-transformed counterparts and preferentially utilize glycolytic metabolism to produce ATP, even in the presence of oxygen, a phenomenon termed aerobic glycolysis [9-11]. Enigmatically, however, the alternative energetic pathway, oxidative phosphorylation, produces significantly more ATP than aerobic glycolysis per molecule of glucose. This begs the question: why do cancer cells preferentially utilize glycolysis, a "less efficient" pathway? Furthermore, contrary to what Warburg originally postulated, a great majority of cancer cells retain the ability utilize oxidative phosphorylation (OXPHOS) via functional, or mainly functional, mitochondria [12]. In contrast to initial beliefs, the purpose for shifting to aerobic glycolysis lies beyond fulfilling the energy requirements of rapidly proliferating cells; rather, increased glycolytic metabolism is utilized to provide the raw materials needed for rapid growth in the form of anaplerotic substrates. These substrates are produced through shuttling of glycolytic pathway intermediates into a variety of other metabolic pathways, such as the pentose phosphate pathway (PPP), the TCA cycle, nucleotide biosynthesis and glycogen synthesis $[4,5,7,8]$. As will be discussed in further detail, one such pathway has remained largely unexplored, that of sphingolipid biosynthesis.

In addition to the role of metabolic alterations at the cellular level in cancer cells, evidence has mounted at both the clinical and epidemiological level that systemic alterations in metabolism may also play a role in oncogenesis, progression and response to treatment. Obesity, hyperglycemia, hyperlipidemia and insulin resistance are correlated with increased risk of cancer development, more rapid disease progression and poorer response to treatment [13]. These disease states are associated with elevated circulating glucose and insulin levels. As such, one proposed mechanism for the increased incidence of cancer in these patients is activation of 
mitogenic signaling pathways by glucose and insulin-like growth factors 1 (IGF1) through the IGF1 receptor (IGF1-R) [14], in addition to increased availability of glucose for uptake by cancer cells preferentially utilizing glucose metabolism. Retrospective studies have also shown that patients being treated with metformin and statins have a decreased incidence of cancer, although at least in some cancers this is believed to be independent of their effects on glucose and cholesterol metabolism, respectively [10, 11, 15-17]. Finally, both in vitro and in vivo studies have shown that both a ketogenic diet, which lowers circulating glucose levels [18], and caloric restriction [19] sensitize cancer cells to chemotherapeutics. Collectively, these studies indicate that alterations in metabolism at the systemic level, more specifically those which increases blood glucose levels, can promote oncogenesis and that metabolic therapeutics may serve to reverse this effect.

\section{Cancer Metabolism Extended: the P entose Phosphate Pathway and Glycogen Synthesis in Cancer}

While one of the most well-known metabolic hallmarks of transformed cells is increased utilization and reliance on glycolysis, the purpose of this aberration is merely as a conduit to further the overall goals of the cancer cell. In contrast to its role in "normal" cells, where it primarily serves to generate both ATP and reducing equivalents for OXPHOS, increased aerobic glycolysis in neoplastic cells functions to provide anaplerotic intermediates for shunting into various metabolic and anabolic pathways to support the requisite increase in biomass of the rapidly proliferating cell. The pentose phosphate pathway (PPP) is one of the key metabolic pathways $[2,8,20]$. Briefly, the PPP receives intermediates from glycolysis (primarily glucose-6phosphate (G6P), fructose-6-phosphate (F6P), and glyceraldehyde-3-phosphate (G3P)) for production of NADPH and ribose-5-phosphate (R5P). R5P is the precursor utilized in nucleotide biosynthesis to maintain rapid DNA synthesis in the highly proliferative phenotype. NADPH is an essential reducing agent in lipid and nucleotide biosynthesis, in addition to being a critical 
cellular antioxidant. As testament to its key role in cancer cell metabolism, and glycolysis' role as a supplier rather than an effector, it was shown that decreased PPP flux and concomitant increased glycolytic metabolism through increased pyruvate kinase $\mathrm{M} 2^{1}$ (PKM2) activity resulted in decreased tumor growth in a xenograft model [21]. Furthermore, increased activity glucose-6phosphate dehydrogenase (G6PD) ${ }^{2}$, either through overexpression or inhibition of negative feedback, was sufficient to transform murine NIH-3T3 fibroblasts and promote tumorogenesis in mice [22]. In relation to the current study, NADPH formation is essential for multiple aspects of sphingolipid metabolism: both in lipid biosynthesis, in forming the fatty acid chain to be added to sphingosine to form dihydroceramide, and in de novo ceramide synthesis itself (Fig. 1).

While many other facets of oncogenic metabolism have been the topic of intense research, the role of glycogen synthesis in this phenotype remains comparatively less explored. As early as 1925, it was shown that highly glycolytic tumor cells present with elevated glycogen levels [23], a phenotype now recognized as a hallmark of many clear cell carcinomas/sarcomas [24-28]. More recent studies have suggested that glycogen formation may function as a protective mechanism by serving as a store of glucose molecules to fuel anaerobic glycolysis during times of external stress [29]. In studies of tumor cell hypoxia, it has been shown that glycogen synthase is initially upregulated in response to oxygen deprivation, in [30-33], with a delayed increase in glycogen phosphorylase after prolonged hypoxia [34]. Furthermore, inhibition of glycogen phosphorylase in pancreatic tumor cells resulted in decreased glucose oxidation, and subsequent reduction in fatty acid and nucleotide biosynthesis [35]. This protective mechanism would arguably play a more important role in the pathogenesis of solid tumors, which are more susceptible to areas of oxygen deprivation; however, evidence does suggest that leukemic cells may be exposed to areas of hypoxia in the bone marrow microenvironment as well $[36,37]$. Glycogen formation is

\footnotetext{
${ }^{1}$ PKM2: pyruvate kinase isoform M2; catalyzes the rate-limiting, ATP-generating step of glycolysis in which phosphoenolpyruvate (PEP) is converted to pyruvate; the M2 form is found in self-renewing cells, and tumor cells

${ }^{2}$ G6PD: glucose-6-phosphate dehydrogenase: the rate-limiting enzyme for entry of G6P into the PPP (via conversion of G6P to 6-phosphogluconate)
} 
catalyzed by glycogen synthase (GS), through addition of UDP-glucose to existing glycogen polymers. UDP-glucose formation depends on the formation of UTP, which relies on nucleotide biosynthesis for its formation, itself being fueled by production of intermediates from the PPP (see a simplified diagram below). Although to the best of our knowledge there are no studies that directly measure the level of UDP-glucose in neoplasms, studies in animal models of diabetes, which also take up elevated levels of glucose, present with elevated levels of UDP-glucose [38, 39]. Lastly, the regulation of GS by glycogen synthase kinase (GSK) has recently become a topic of interest in cancer signaling, though its exact role in carcinogenesis is still largely unclear and thus will not be discussed here (a review on the topic can be found in ref. [40]).

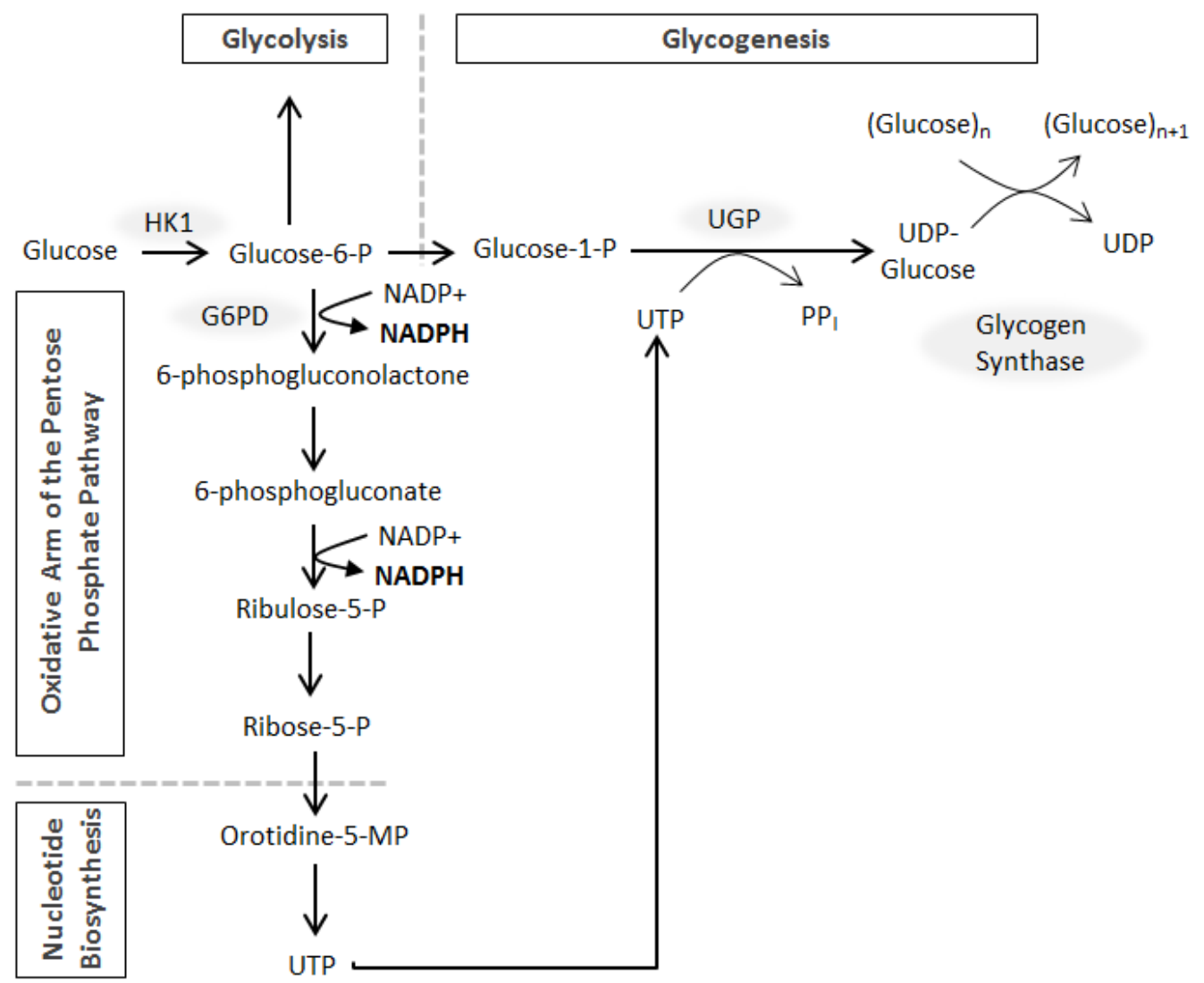

\section{Glycolytic Inhibitors / PPP Inhibitors in Cancer}

Given the significant role that aberrant metabolism plays in the neoplastic cell phenotype, development of therapies targeting the key control enzymes in the aforementioned pathways is 
being actively pursued $[2,41-43]$. Current agents are comprised of both pharmacological and RNAi mediated inhibition of nearly all facets of neoplastic metabolism, utilizing both established metabolic therapies and novel rational drug design [2].

Despite promising results at the pre-clinical and clinical level, targeting the deregulated bioenergetic and anabolic pathways in neoplastic cells is subject to the same critical pitfall as genotoxic therapies, which themselves target cells of the highly proliferative phenotype. "Normal" rapidly dividing cells, such as bone marrow-derived cells or gut epithelium, are subject to the non-discriminant effects of cytotoxic drugs, resulting in sometimes severe side effects associated with chemotherapy. Common short-term effects includenausea, emesis, fatigue, diarrhea, cachexia, peripheral neuropathy, myalgia, alopecia and myelosuppression; long-term side effects may include cardiotoxicity, ovarian failure in women, sterility in men, chemotherapyinduced leukemia and cognitive dysfunction [44], notwithstanding drug-specific toxicities and side effects. Furthermore, activation of $\mathrm{T}$ lymphocytes (i.e. rapid clonal expansion) relies on increased glucose uptake and reliance on aerobic glycolysis [45]. T lymphocytes play a key role in immune-derived targeting and eradication of cancer cells through recognition of tumorassociated antigens [46]. Tumor cells have been shown to avoid detection from the immune system by inducing apoptosis of immune cells such as lymphocytes and antigen presenting cells, both in the surrounding microenvironment and systemically [47-50]. Further dampening of this immune response via inhibition of biometabolic pathways could be seen as adding insult to injury. However, it is proposed that there exists a therapeutic window in which treatments could target neoplastic/malignant cells, for example through isoform-selective therapies or careful drug titrations (reviewed in [51]). Another alternative involves the use of combinatory therapies, with one advantage being a lower effective dose of each individual drug, an approach which is commonplace in modern day chemotherapeutics [52]. A growing number of studies point to the therapeutic potential of combining metabolic inhibitors with targeted therapies $[53,54]$, such as the combination of hexokinase-II inhibitor 3-BrOP with mTOR inhibitor rapamycin [55]. In the 
current study, we have provided support for this approach, in showing potent synergism exists between two metabolic inhibitors, 2-deoxyglucose ${ }^{3}$ (2-DG) and 6-aminonicotinamine ${ }^{4}$ (6-AN), and $\mathrm{ABT}-263^{5}$, a targeted inhibitor of the pro-apoptotic BCL2 family.

\section{Sphingolipids: Membranes and More}

Sphingolipids, originally sphingosin or "sphinx-like", were named in respect of their enigmatic and complex nature by Johann Thudicum almost 150 years ago. Since that time, it has been established that hundreds of higher order sphingolipid species exist, thousands when taking into account varying chain lengths, a statistic daunting enough to scare off even the most dedicated of biologists. However, their role in cancer pathogenesis is undisputed, so though they may be the in-laws of the cancer biology family, they are here to stay and thus must be discussed. After a few glasses of wine, you may even grow to enjoy them. For the purpose of this discussion, a brief overview of sphingolipid metabolism will be presented as it relates to the current study. For a more thorough understanding of this topic, consult your nearest black hole (or the following review by Gault, Hannun and Obeid [56]).

Sphingosine, an amino alcohol of 18 carbons formed from the condensation of palmitoyl $\mathrm{CoA}$ and serine, is the backbone of the entire sphingolipid family. Important players in this family are:

i) ceramide, formed via $\mathrm{N}$-acylation of a fatty acid chain (14-26 carbons) to the amide group of sphingosine by ceramide synthase (CerS); the central hub of all sphingolipid metabolism

ii) sphingomyelin (SM), a key membrane phospholipid, formed via addition of phosphocholine (or less commonly phosphoethanolamine) to the $\mathrm{C} 1$ hydroxyl of ceramide via sphingomyelin synthase (SMS)

\footnotetext{
${ }^{3}$ 2-deoxyglucose (2-DG): inhibitor of the rate-limiting enzyme of glycolysis, hexokinase (HK) through competitive inhibition with glucose

${ }^{4}$ 6-aminonicotinamine (6-AN): inhibitor of 6-phosphogluconate dehydrogenase, an enzyme of the PPP which catalyzes the conversion of 6-phosphogluconate to ribulose-5 phosphate

${ }^{5}$ ABT-263 (navitoclax): structural analog of ABT-737; inhibitor of the BCL2 family anti-apoptotic proteins, namely Bcl-2, Bcl-w and Bcl-xL; induces apoptosis
} 
iii) glucosylceramide (GlcCer), formed via addition of UDP-glucose to ceramide via glucosylceramide synthase (GCS); point of entry into the higher order glycosphingolipids

iv) sphingosine-1-phosphate (S1P), formed via addition of a phosphate group to sphingosine by sphingosine kinase

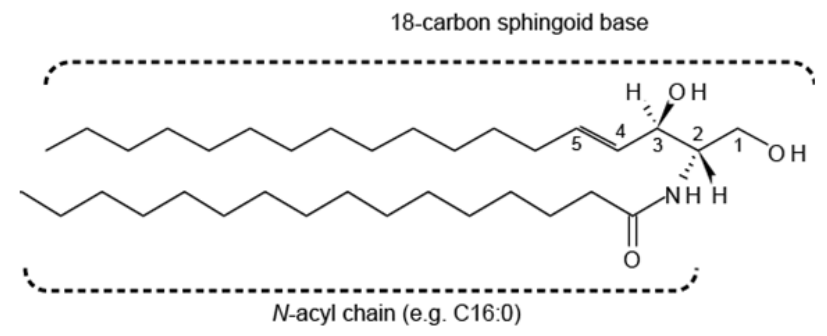

Ceramide. Siskind et al. 2008

Under normal homeostatic conditions, ceramide can be generated via three pathways: 1) de novo synthesis 2) sphingomyelin hydrolysis 3) the salvage pathway (S1P breakdown). The de novo pathway relies on a critical enzyme, ceramide synthase (CerS), to catalyze the addition of a fatty acyl group to sphinganine to form (dihydro)ceramide (Fig. 1). As alluded to prior, part of the complex nature of sphingolipids is their ability to differ by fatty acid chain length. Six different isoforms of CerS exist and although some overlap exists, each isoform preferentially utilizes a specific fatty acyl chain length(s) [57]. For example, CerS5 preferentially uses long-chain fatty acids of 14 or 16 carbons to form either $\mathrm{C}_{14}$-Ceramide or $\mathrm{C}_{16}$-Ceramide. This has important implications for targeted therapies against sphingolipid enzymes, as it is postulated that ceramides (and derivatives such as glycosphingolipids) may play markedly different roles depending on the fatty acid chain length [58-60].

Ceramides are synthesized de novo in the endoplasmic reticulum (ER), then transported to the Golgi. On the cytoplasmic face of the Golgi, GCS catalyzes the addition of UDP-glucose to form GlcCer. An important implication of this localization is that GCS has access to cytoplasmic contents and is not restricted to their transport across the Golgi membrane, a fact that will be of importance in discussion of its hypothesized role in cancer cell metabolism. 
In addition to their role in regulation of membrane dynamics, sphingolipids are bioactive lipids involved in intracellular signaling, including roles in inflammation, cellular proliferation, oxidative stress and cell death. As defined by Hannun and Obeid, sphingolipids are regarded as bioactive due to the observation that "changes in (their) levels result in functional consequences" [61]. Among the many cellular functions in which sphingolipids play a role, one of the best characterized is their role in programmed cell death, or apoptosis [62]. Over 20 years have passed since the seminal work linking ceramide production to apoptosis was first published [63]. Since that time, there has been no shortage of studies linking cytokines, external stressors and apoptotic stimuli to production of ceramide and induction of apoptosis. Briefly, an external stimulus, such as TNF- $\alpha$, leads to production of ceramide via activation of a metabolic enzyme, such as sphingomyelinase, which degrades SM to ceramide. Ceramide may then exert its proapoptotic effects through multiple mechanisms: 1) formation of ceramide-enriched domains and subsequent modulation of receptors or signaling molecules or 2) contributing to induction of mitochondrial outer membrane permeabilization (MOMP) through formation of ceramide channels in the mitochondrial outer membrane (MOM). (reviewed in [64]). The control of intracellular ceramide in response to cytotoxic agents is an important determinant in the outcome following a cytotoxic insult and thus has been implicated in a variety of disease states, cancer notwithstanding.

\section{Glycosphingolipids and Cell Signaling: Implications for Cancer}

In addition to their well-characterized role as structural components in the plasma membrane, certain species of GSLs have been widely implicated as pro-proliferative bioactive lipids in a variety of pathologies, including metabolic, kidney, and cardiovascular diseases, in addition to neoplasms [65-67]. Most evidence has pointed to the role of lactosylceramide and gangliosides as the major GSL players in this phenotype. GSLs have been shown to act as key players in various cellular signaling pathways, through formation of GSL micro- and macrodomains in the plasma 
membrane, termed "glycosynaptic membranes" [68], in which they interact with transmembrane growth factor and cytokine receptors [69, 70], intracellular signal transducers [71], and cell adhesion proteins $[72,73]$.

Of particular interest in recent decades is the role of GSLs in cancer. Clinical evidence shows that tumor cells have distinct glycosphingolipid profiles compared to non-transformed cells [50, $74,75]$, a phenotype associated with aberrant cell-cell adhesion and intracellular signaling, which play a significant role in tumor progression, metastasis, and response to treatment [76]. Much progress has been made in elucidating the mechanisms by which GSLs play a pathogenic role in solid tumors (for review, see ref $[68,77,78]$ ). In brief, such mechanisms include: i) association of GSLs with cell surface receptors and subsequent modulation of cellular signaling pathways, such as inhibition of tyrosine kinase activity of EGFR in breast cancer cells [74]; ii) modulation of integrin receptor function and subsequent control of invasion and motility, such as in bladder cancer [73]; iii) regulation of non-receptor intracellular signaling proteins, such as c-Src and Rho in melanoma [71]; and iv) "shedding" of GSLs into the extracellular tumor environment, inhibiting localized immune response and effectively paving the way for invasion and metastasis [47, 49]. Similarly, hematological malignancies have been found to have distinct GSL expression patterns in relation to disease subtype [79-84], although in contrast to solid tumors, less is known about their functional role in pathogenesis of blood cancers. As is recurrently the case in cancer biology, growing evidence suggests that the effect of GSL on cancer pathogenesis is both tumorand GSL-species specific [85]. GSLs themselves are an extremely complex group of lipids composed of thousands of higher order species [86]. Despite this complexity, certain GSL subspecies have garnered particular interest due to their variable expression in tumors, namely those of the ganglioside ${ }^{6}$ family. While overexpression of GSLs is associated with increased metastatic potential in some cancer types such as lymphoma and melanoma, it is inversely correlated with

\footnotetext{
${ }^{6}$ Ganglioside: a glycosphingolipid composed of a lactosylceramide backbone with the addition of sialic acid moieties
} 
invasion and metastatic potential in others, such as bladder and liver cancer (reviewed in [85]). Nevertheless, while aberrant GSL expression is increasingly considered a hallmark of cancers and may be useful as a biomarker in measuring disease progression, arguably one of those most extensively studied aspects of sphingolipid biology in cancer is its role in chemotherapy-induced apoptosis, or evasion thereof.

In addition to their established role in proliferation, invasion and metastasis in tumors, GSLs have also been implicated in multidrug resistance (MDR). Treatment of cancer cells with chemotherapeutics elevates levels of the proapoptotic sphingolipid ceramide in a multitude of cancer cell lines during mitochondrial induced cell death $[62,64,87,88]$. As a means of evading cell death, many drug-resistant cell lines reduce cellular ceramide levels via metabolism to other sphingolipid members, one such mechanism being conversion to GlcCer [65, 89]. Correspondingly, elevated levels of GCS and GlcCer are widely implicated in MDR in many cancers $[90,91]$. The mechanism behind this observed phenomenon has been well characterized both at the in vitro and in vivo level. Briefly, a growing body of data suggests a strong relationship between GCS, MDR1, p-glycoprotein, drug efflux and resistance. P-gp is a membrane transport protein implicated in drug efflux-dependent and -independent resistance, encoded by the MDR1 gene. P-gp is also responsible for the transport of GlcCer from the cytosolic to luminal face of the golgi membrane [92], where it can be converted to more complex GSL species [93]. Studies have shown a direct correlation between increased drug resistance, GCS expression and p-gp message and protein levels [94]. It has also been shown that both GlcCer and GCS lead to increased MDR1 expression, through c-Src and beta-catenin signaling $[91,95]$. This effect can be abated through pharmacological or genetic inhibition of GCS, which also resensitizes resistant cells to chemotherapeutics [96, 97]. Taken together, GCS plays a clear role in cancer pathogenesis and consequently has been an attractive target for the development of anti-neoplastic pharmaceuticals as both a primary treatment and a combinatorial treatment with cytotoxic therapies for the treatment of drug-resistant malignancies [98]. 
As a final note, it is worth mentioning that the sphingolipids lactosylceramide and sphingosine-1-phosphate have been widely implicated in tumoro- and leukemogenesis, including roles in proliferation, metastasis and resistance, however are outside the scope of the current review. The reader may reference an in-depth review by Ogretman and Hannun for more information on this topic [99].

\section{GCS Inhibitors in Cancer}

In keeping with the growing body of evidence implicating GSLs in cancer pathogenesis, significant investment has been made into the development of targeted GCS inhibitors. Despite resounding evidence that GCS acts as a potent sensitizing agent to cytotoxic and metabolic drugs, there persists conflicting views in the literature as to the exact mechanism by which GCS inhibitors exert their effects, and to what end sphingolipid metabolism plays a role. For this reason, a very brief overview of the evidence surrounding this topic will be presented, as the field will surely evolve in its understanding in the coming years.

As previously discussed, there exists a positive correlation between p-gp and GCS levels in MDR. In targeting GCS as a means of reversing MDR, it has been shown in a wide range of cancer types that pharmacological and genetic inhibition of GCS synergizes with both standard of care chemotherapeutics [100-104] and with metabolic inhibitors such as resveratrol [105]. Given the relationship between GCS and p-gp in MDR, in addition to the fact that ceramide analog GCS inhibitors $^{7}$ are also substrates of $\mathrm{p}$-gp, the question was posed as to whether MDR reversal was truly a result of GCS, and not p-gp, inhibition. Evidence exists for both the former [106] and the latter [98, 107], indicating that indeed this topic must be explored in greater depth.

What is almost undisputed in the literature, however, is that the sensitizing effect of GCS inhibition on cyototoxic therapies occurs almost exclusively in cells with established drug

\footnotetext{
${ }^{7}$ Ceramide analog GCS inhibitors: as their name suggests, these inhibitors are ceramide analogs which compete for binding on GCS;
} 
resistance, as opposed to the parental, drug-sensitive cell line [98, 108]. In fact, one study has shown that treatment of non-resistant cells with PDMP and PPMP, ceramide analog inhibitors of GCS, results in resistance to the genotoxic drugs doxorubicin and cytarabine in a leukemia model [109], a phenomenon confirmed by data in the present study.

While the mechanistic basis of sensitization by GCS inhibitors remains to be and must be elucidated, the fact remains that an overwhelming amount of evidence points to its efficacy. It is for this reason that its use in the clinic for the treatment of drug-resistant cancers has been advocated. The GCS inhibitor eliglustat tartrate (Genz-112638) is currently in phase III clinical trials for Gaucher's Disease ${ }^{8}$ patients, and seems to be both effective and well tolerated. As such, this could be a promising option for the first human trials therapeutically targeting GCS, particularly in the context of drug resistant cancer. It should be noted, however, that because Genz-112638 [110] is a substrate of p-gp, it very poorly penetrates the blood brain barrier and thus would not be a viable option for the treatment of primary or metastatic brain tumors. However, design of a GCS inhibitor that would cross the BBB is currently an active area of research [111].

\section{Cross-talk between Glycolysis and Sphingolipid Biosynthesis}

Given that GCS utilizes UDP-glucose to generate GlcCer, it would follow that increased glucose availability might elevate GSL levels. Despite this rather straightforward observation, a limited amount of data exists on the potential connection between these two entities, none of which has been evaluated in transformed cells. In vitro work has shown that renal epithelial cells cultured in high glucose have both elevated GlcCer and increased proliferation [38]. Work in rat models of type 1 diabetes mellitus (DM1) indicates a correlation between glucose uptake and GSL production. In these models, both UDP-glucose [112] and GSL levels [38, 39] are elevated

\footnotetext{
${ }^{8}$ Gaucher's Disease: an autosomal recessive lysosomal storage disorder due to a defiency of GBA, leading to accumulation of GlcCer in certain organs
} 
in the kidney in response to increased plasma concentrations of glucose. Conversely, inhibition of GSL production via targeting GCS improves glucose tolerance in animal models of DM1 [113]. Furthermore, reduction of GSL levels via inhibition of GCS increases both glucose uptake and glycolytic metabolism in leukemia cells [114], suggesting that a compensatory mechanism may exist by which the cell restores GSL levels through increased uptake and metabolism of the requisite substrates. Although these studies establish a connection between glucose availability, substrate production and GSL levels, they are inherently confounded by either: 1) the presence of disease states, for which the presence of external variables cannot be excluded or 2) the aberrant signaling pathways characteristic of transformed cells which undoubtedly influence glycolytic metabolism beyond glucose uptake.

\section{Conclusions}

Despite the fact that increased glucose uptake and utilization is a hallmark of most cancers, and elevated glycosphingolipids are widely accepted as a prognostic marker of cancer progression and metastatic potential, an objective relationship between the two has yet to be drawn. Herein we have established a link between the distinct, yet clearly interrelated metabolic fields of glycolytic and glycosphingolipid metabolism. We demonstrate that increasing glucose uptake and utilization in a non-transformed cell line, FL5.12, is sufficient to increase the levels of GSL, while withdrawing glucose from these same cells causes their dramatic depletion. Inhibition of glycolysis and the PPP is sufficient to deplete GSL levels in the same manner in both FL5.12 cell lines. Furthermore, we also present findings that this link persists in hematological malignancies and that manipulation of glycolytic and pentose phosphate pathway metabolism influences GSL levels in a leukemia cell line. Finally, we show that in a leukemia cell model, metabolic inhibitors 2-DG and 6-AN synergize with pro-apoptotic BCL-2 inhibitor ABT-263 in inducing apoptosis. 
Overall, these data demonstrate a clear link between glucose uptake and utilization and the production of glycosphingolipids. 


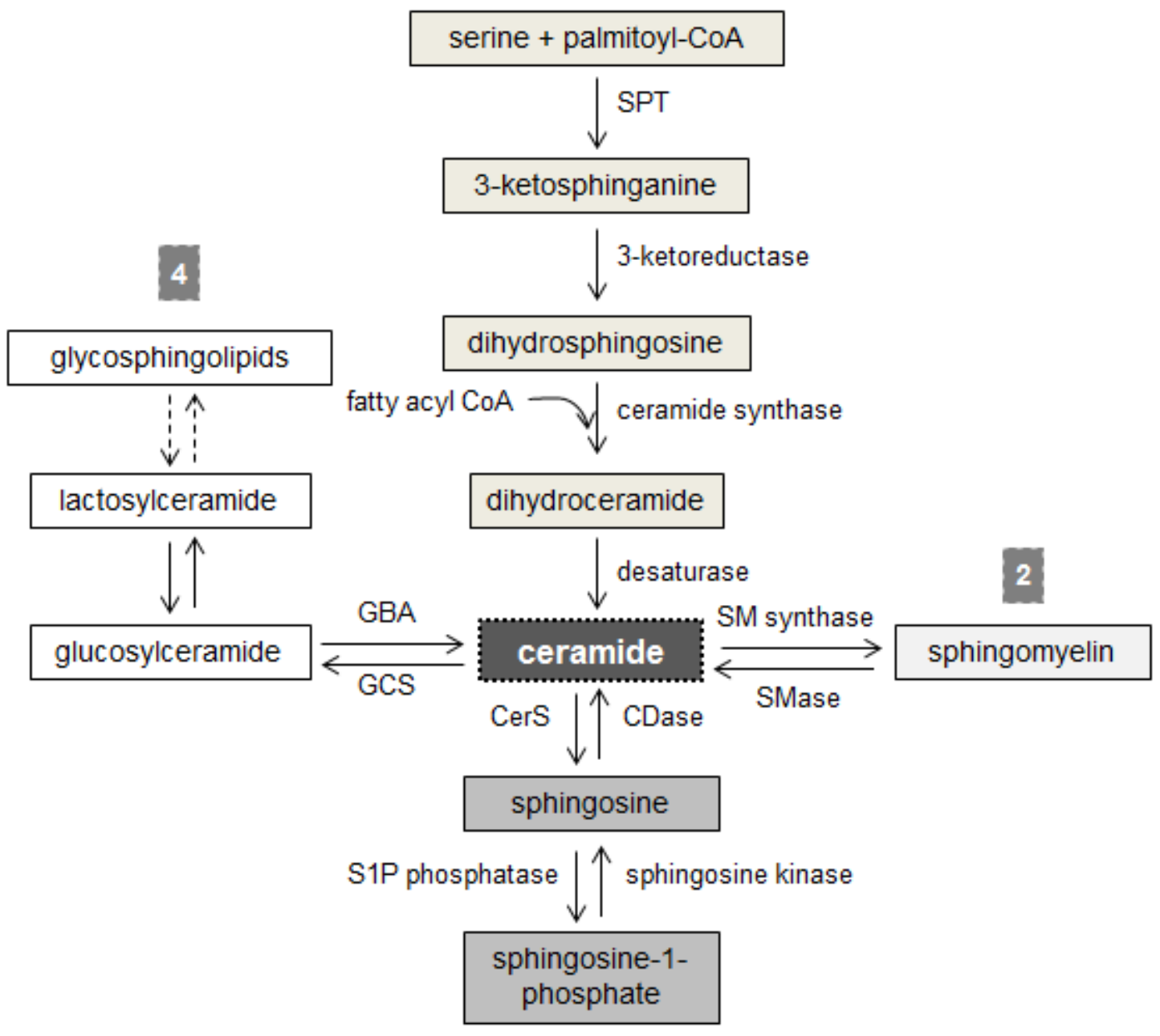

3

Figure 1: An overview of sphingolipid metabolism.

Formation of ceramide occurs through the de novo pathway (1), SM hydrolysis pathway (2), the salvage pathway (3), or $\beta$-Glucocerebrosidase (GBA) breakdown (4). The ratio of ceramide to glucosylceramide is an important factor in the survival of cells. Glucosylceramide is formed through addition of UDP-glucose to ceramide by glucosylceramide synthase (GCS) or the breakdown of lactosylceramide. 


\section{MATERIALS AND METHODS}

\section{Cell Culture and Reagents}

FL5.12 WT and HG cells were kindly provided by Dr. Jeffrey Rathmell (Duke University Medical Center, Durham, NC) [115]. Human leukemia cells were purchased from ATCC. All cells were maintained in HyClone RPMI 1640 (Thermo Scientific \#SH 30027) medium containing 10\% FBS supplemented with 2 mM L-Glutamine, 10 mM HEPES (Gibco 15630-80) and 1X pen-strep (Gibco 15140-122); FL5.12 cells were additionally supplemented with $2 \mathrm{ng} / \mathrm{ml}$ recombinant mouse IL-3 and 1X $\beta$-mercaptoethanol. FL5.12 cells were maintained in the $\log$ growth phase between $5 \times 10^{5}$ and $2 \times 10^{6} \mathrm{c} / \mathrm{ml}$. Leukemia cells were maintained in the log growth phase between $1 \times 10^{5}$ and $2 \times 10^{6} \mathrm{c} / \mathrm{ml}$.

\section{Cell Viability Assay}

Cells growing in the log phase were seeded in 96- well dishes $(2,500$ FL5.12, U937, or 5,000 OCI AML 3 or 7,500 K562 cells per well) and immediately treated with the indicated drug concentrations in a total volume of $200 \mu \mathrm{l}$ per well. All treatments were done in triplicate. 2-DG (\#14325) and 6-AN (\#10009315) were obtained from from Cayman and ABT-263 (cat\#CTA263) from Chemietek (Indianapolis, IN, USA). Cells were treated for 48 hours, then incubated with 10\% (20 $\mu$ l) Alamar Blue reagent (cat\#DAL1100) from Invitrogen (Grand Island, NY, USA). for 4 hours. Fluorescence of Alamar Blue reduction was determined on a BioTek HT Synergy plate reader (540 nm excitation, $594 \mathrm{~nm}$ emission). Wells containing only complete RPMI media and vehicle plus $20 \mu \mathrm{l}$ of Alamar Blue were averaged and subtracted from all experimental readings. Drug treatment regimens were then normalized to either vehicle treated 
cells or to wells containing only the $\mathrm{IC}_{30}$ of the indicated drug using a high-throughput method in excel (see below). Each graph shown is a representative experiment of at least three biological replicates unless otherwise indicated.

\section{Western Blot Analysis}

$5 \times 10^{6}$ cells were harvested and lysed via sonication for $30 \mathrm{~s}$ in $350 \mu 1$ of RIPA lysis buffer (NEBL \#9806S) with 100X protease and phosphate inhibitors. Protein concentrations were determined using BCA protein assay reagent from Pierce (\#23223 and \#23224). Cell homogenate was spun for 5 minutes at 500xg to pellet unlysed cellular debris. Supernatant was transferred to a new tube. Briefly, supernatant was diluted 1:10 and $25 \mu 1$ of this dilution was added to $475 \mu 1$ of BCA reagent. Pre-diluted BSA protein standards were utilized for preparation of a standard curve. 25 $\mu \mathrm{l}$ of BSA standard and $25 \mu \mathrm{l}$ of lysis buffer was added to $450 \mu \mathrm{l}$ of BSA reagent. Standards and unknowns were then vortexed to mix and incubated in a $37^{\circ}$ water bath for 30 minutes. $200 \mu 1$ of standard and unknown were then plated in duplicate on a 96-well plate and measured on a spectrophotometer at $562 \mathrm{~nm}$. Unknown values were extrapolated to the standard curve for quantification. Using these values, protein was diluted to $2 \mu \mathrm{g} / \mathrm{ml} .40 \mu \mathrm{g}(20 \mu \mathrm{l})$ of total protein was used for standard western blot procedure. Samples were boiled at $98^{\circ}$ for 5 minutes before being run on SDS-PAGE gel (BioRad \#345-0033) at 165V for approximately 30 minutes. The gel was then transferred using the iBlot Transfer System (Novex). Membranes were blocked in TBS$\mathrm{T}$ with $5 \%$ milk for 1 hour at room temperature. Primary antibody was added in the following dilutions: 1:1000 anti-GLUT1 (Santa Cruz \#SC-7903), 1:2500 anti-HK1 (Cell Signaling \#2024); 1:10,000 anti-actin (Sigma \#A5441), 1:10,000 anti-tubulin (Sigma \#T5168). Anti-mouse and antirabbit were added at a dilution of 1:10,000. Chemiluminescent detection was performed using Pierce ECL Western Blot Substrate (\#32106) from Thermo Scientific according to manufacturer's protocol. 


\section{In Situ Glucosylceramide Synthase Activity Assay}

5mg NBD-C ${ }_{6}$-Ceramide complexed with BSA (Life Technology \#N22651) was dissolved in 150 $\mu$ sterile $\mathrm{dH}_{2} \mathrm{O}\left(0.5 \mathrm{mM}\right.$ NBD- $\mathrm{C}_{6}$-Ceramide and $0.5 \mathrm{mM}$ BSA $)$ and stored at $-20^{\circ} \mathrm{C} .1 \times 10^{6}$ cells were plated in a 6-well plate in $2 \mathrm{ml}$ of complete RPMI 1640 media. $20 \mu \mathrm{M}$ PDMP was added to the appropriate wells; remaining cells received DMSO as vehicle. Cells were incubated for 2 hours at $37^{\circ} \mathrm{C}$. All cells then received $2 \mathrm{uM}$ of NBD-C $\mathrm{C}_{6}$-Ceramide and were incubated at $37^{\circ} \mathrm{C}$ for 30 minutes. Cells were collected, spun at $1000 \mathrm{xg}$ for $5 \mathrm{~min}$ at $4{ }^{\circ} \mathrm{C}$, and supernatant was removed. Cells were washed $1 \mathrm{X}$ by adding ice-cold PBS (1000xg, 5 min, $\left.4^{\circ} \mathrm{C}\right)$. Supernatant was removed. Lipids were extracted by Bligh and Dyer method [116]. Briefly, cells were resuspended with 260 $\mu l$ of ice-cold PBS and transferred to glass tubes. $666 \mu \mathrm{l}$ of methanol was added to the cells and vortexed 2x30s. Cells were then kept on ice for $10 \mathrm{~min} .333 \mu \mathrm{l}$ of chloroform and $333 \mu 1$ of water was added to tubes, which were vortexed two times for 30 s then spun at 3000rpm for 5 min at room temperature. The lower phase (containing the lipids) was transferred to a new set of glass tubes and lipids were dried down by nitrogen gas. Lipids were then resuspended in $30 \mu 1$ of chloroform/methanol (2:1, v/v) and loaded onto TLC plates (Millipore \#1.05644.0001) for separation. NBD-Glycosphingolipids were used as standards. The chromatogram was developed in a solvent system consisting of chloroform/methanol/30\%ammonium hydroxide/water (350:150:18:7: vol/vol). TLC plates were scanned on a BioRad phosphorimager. Band density was quantified by Quantity One software $\left(\right.$ count $\left./ \mathrm{mm}^{2}\right)$. NBD-GlcCer were normalized to total (NBD-Ceramide + NBD-GlcCer), and the normalized to total cell number and time.

\section{Quantitative Real-Time Reverse Transcription PCR}

Total RNA was extracted using EZNA Total RNA Kit I (OMEGA bio-tek \#R6834) according to the manufacturer's protocol. The concentration and quality of total RNA preparations were evaluated by NanoDrop. cDNA was synthesized from 1 ug of total RNA using the iScript cDNA 
Synthesis Kit for first-strand synthesis (BioRad \# 170-8890). Quantitative real-time PCR (qPCR) was performed on a Bio-Rad CFX96 Real-Time detection system using SsoFast EvaGreen Supermix (BioRad \# 172-5202). Standard reaction volume was $25 \mu 1$ containing $12.5 \mu 1$ Supermix, $9.5 \mu \mathrm{dH} 2 \mathrm{O}$ (Sigma), $400 \mathrm{nM}$ specific oligonucleotide primers, and $25 \mathrm{ng}$ of cDNA template. $\beta$-Actin was used as reference gene. The PCR reaction was carried out as follows for UGCG, GBA and $\beta$-actin: enzyme activation $95^{\circ} \mathrm{C}, 30 \mathrm{~s}$; denaturation $95^{\circ} \mathrm{C}, 5 \mathrm{~s}$; annealing $60^{\circ} \mathrm{C}$ $5 \mathrm{~s} ; 40$ cycles total. For FL5.12 cells, the $\Delta \Delta \mathrm{C}_{\mathrm{T}}$ method was used, and HG was normalized to WT. For leukemia cells, absolute quantification of expression was calculated via normalization to a previously validated standard curve for $\beta$-actin. Primers were validated for temperature and efficiency prior to use in qPCR. Primer sequences are as follows:

\begin{tabular}{|l|l|l|}
\hline Gene & Sense & Anti-Sense \\
\hline hACTB & ATTGGCAATGAGCGGTTCC & GGTAGTTTCGTGGATGCCACA \\
\hline hUGCG & GAATGGCCGTCTTCGGGTT & AGGTGTAATCGGGTGTAGATGAT \\
\hline hGBA & CCGATGGCTCTGCTGTTGTG & CAGGTAGGTGTGAATGGAGTAGC \\
\hline mUGCG & CCTTGTTCGGCTTCGTGCTCTTC & TGCTATACGGCTGTTTGTCTGTTGC \\
\hline mGBA & TGGATGCTTATGCTAAGTATGG & CACGGGAAATGAAGTCTCTCTG \\
\hline mACTB & AGATTACTGCTCTGGCTCCTAG & CCTGCTTGCTGATCCACATC \\
\hline
\end{tabular}

\section{Glucose Uptake}

$1 \times 10^{6}$ cells were plated in glucose-free RPMI 1640 media supplemented with $10 \%$ dialyzed FBS. Cells were incubated at $37^{\circ} \mathrm{C}$ for 30 minutes following plating to allow equilibration with media. Following incubation, cells were given $25 \mu \mathrm{l}$ of ${ }^{14} \mathrm{C}$ deoxy-glucose $(0.1 \mu \mathrm{Ci} / \mu \mathrm{l})$ for one hour, then washed three times with ice cold PBS. Cells were lysed in $500 \mu \mathrm{l} 0.1 \%$ SDS. $400 \mu$ l of lysate was added to $5 \mathrm{ml}$ Microscint 40 scintillation fluid (Perkin Elmer) and mixed well by shaking. Counts were measured on a Tri-Carb 2910 liquid scintillation analyzer (Perkin Elmer). Remaining lysate 
was quantitated with the BCA Assay as described above. Counts were normalized to $\mu \mathrm{g}$ protein concentration.

\section{Intracellular Lipid Measurement}

$5 \times 10^{6}$ cells were seeded in $10 \mathrm{~cm}$ dishes containing complete RPMI without antibiotics and treated with the indicated $\operatorname{drug}(\mathrm{s})$ or appropriate vehicle in biological triplicates. At the indicated times, cells were harvested, washed two times in $5 \mathrm{~mL}$ of ice cold PBS, then cell pellets were snap frozen in liquid nitrogen. Quantification of sphingolipid species was performed by the Lipidomics Core Facility at the Medical University of South Carolina (MUSC) on a Thermo Finnigan TSQ 7000, triple-stage quadrupole mass spectrometer operating in a Multiple Reaction Monitoring (MRM) positive ionization mode as described [117]. Excess lipids were obtained and extracted using the Bligh and Dyer method. Data were normalized to total lipid phosphate.

\section{Statistical Analysis}

A one-way ANOVA with Halm-Sidak post-test was used for samples $n>2$. A two-tailed t-test was used for samples where $n=2$. Unless otherwise indicated: all data points represent the compilation of at least three biological triplicates; data are represented as average $+/-\mathrm{SD}$; dose-response graphs are a representative graph of an experiment conducted in triplicate; significance was dictated as having a p-value $<0.05$. 


\section{RESULTS}

\section{Glucose Availability Dictates Glycosphingolipid Levels in Highly Glycolytic Cells}

In order to determine whether glucose availability in and of itself is sufficient to drive GSL production we utilized the murine IL-3 dependent FL5.12 hematopoietic progenitor cell line overexpressing the glucose transporter Glut-1 and the rate-limiting glycolytic enzyme HK-1 (herein FL5.12 HG) [115] (Fig. 2A). This cell line represents a model of highly glycolytic cells independent of intracellular or extracellular alterations seen in disease states. As expected, FL5.12 HG cells took up 83-fold more glucose as compared to their wild-type counterparts (Fig. 2B). Furthermore, over-expression of $\mathrm{HK} 1$ in $\mathrm{HG}$ cells leads to a significant decrease in their sensitivity to treatment with the HK-1 competitive inhibitor $2-\mathrm{DG}\left(\mathrm{IC}_{50}=0.33 \mathrm{mM}\right.$ vs $1.7 \mathrm{mM}$ for wild-type and HG, respectively) (Fig. 4A). This was further confirmed by treatment of both cell lines with a single dose 2-DG and determining the relative cell viability. At $1 \mathrm{mM}$ of 2-DG the cell growth of wild-type cells was inhibited by $65 \%$, whereas HG cells were only inhibited by 27\% (Fig. 2C).

Previous studies indicated that increased glucose availability resulted in increased GSL levels in DM1 mice [39], therefore we assessed if the same phenomenon would occur in our model of highly glycolytic cells. Indeed, increased glucose availability resulted in elevated GSL levels in FL5.12 HG cells compared to wild-type cells (Fig. 3A). This led us to question whether glucose withdrawal would correspondingly result in decreased GlcCer levels. Indeed, wild-type cells withdrawn from glucose for 18 hours showed a marked decrease in GlcCer levels compared to cells continuously cultured in glucose (Fig.3B). 
To investigate the extent to which glucose availability impacts enzymatic control of GlcCer formation, we measured the expression and activity of GCS and $\beta$-Glucocerebrosidase (GBA), the enzymes responsible for the anabolic and catabolic formation of GlcCer, respectively (Fig. 3C). Although GlcCer levels were dramatically elevated in HG cells over wild-type, increased glucose availability did not significantly alter the expression of GCS or GBA (Fig. 3C). Moreover, GCS activity was also not increased in FL5.12 HG cells compared to wild-type (Fig. 3D).

Collectively, these data indicate that glucose availability impacts GSL levels, and that in nontransformed cell lines increased GSL production appears to be a substrate driven process relatively independent of GCS expression or activity.

\section{Inhibitors of Glycolytic Metabolism and the Pentose Phosphate Pathway Decrease Glycosphingolipid Levels}

Given that glucose availability plays a clear role in GSL formation (Fig.2B and 3A), we determined whether selective inhibition of bioenergetic pathways downstream of glucose uptake would decrease GSL levels. FL5.12 cells were treated in a dose response manner with 2-DG or 6AN to establish the respective $\mathrm{IC}_{50}$ of each cell line for these inhibitors (Fig. 4A-B). WT and HG cells were then treated for 8 hours with 2-DG or 6-AN $\mathrm{IC}_{50}$ and total hexosylceramide (glucosyland galactosylceramide) levels were measured via HPLC-MS/MS. As shown in Fig. 4C, hexosylceramide levels decreased following treatment with 2-DG in both WT and HG cells. Treatment with 6-AN also decreased hexosylceramide levels in both cell lines, however this effect was blunted in HG cells, an interesting result given that HG cells were found to be slightly more sensitive to 6-AN.

Overall, these data support the hypothesis that GSL levels are at least in part influenced by the production of substrates produced via glycolysis and the pentose phosphate pathway. 


\section{Glycosphingolipid Levels in Leukemia Cells are Primarily Dictated by GCS Activity}

FL5.12 HG cells provided an excellent, syngeneic in vitro model for establishing a relationship between increased glucose availability and GSL production, however they inherently lack the aberrations in intracellular signaling present in cancer cells. In order to examine if this relationship persists in transformed cells, we utilized four leukemia and lymphoma cell lines (collectively "leukemia" cell lines for simplicity), U937, OCI AML3, RAJI and HEL (Fig. 5A). Baseline GlcCer levels were measured via HPLC-MS/MS. GlcCer levels were elevated in U937 and OCI AML3 cell lines, while decreased in RAJI and HEL when compared to cultured human cord blood CD34+ cells (CB12011A) (Fig. 5B). Given that increased glucose availability elevated GlcCer levels in our model of highly glycolytic FL5.12 cells, we examined whether leukemia cells with elevated GlcCer also took up more glucose.. U937 and OCI AML3 cells took up elevated, albeit non-significant glucose compared to RAJI and HEL cells (Fig. 5C).

To elucidate the extent to which glucose availability correlates with enzymatic GlcCer production in these cell lines, we again measured GCS expression and activity. Similar to FL5.12 cells, there was no significant change in the mRNA expression of either GCS or GBA across the leukemia cell lines (Fig. 6A and 6B). In contrast to FL5.12 cells, however, GCS activity positively correlated with GlcCer levels in our panel of leukemia cells (Fig. 6C). Collectively, these results suggest that increased GlcCer levels in leukemia cell lines may be primarily influenced by increased GCS activity. Glucose availability may influence baseline GlcCer levels in some leukemia cells, perhaps through the production of substrates formed during and downstream of glucose metabolism.

\section{Treatment of Drug Sensitive Leuk emia Cells with Sublethal Doses of GCS Inhi bitors Confers Resistance to Doxorubicin}

A growing body of data indicates that GCS inhibition sensitizes to antineoplastic agents in the context of MDR [89-93], while a recent study showed that in that context of drug-sensitive 
cells, it inhibition of GCS may play a cytoprotective role upon combination with genotoxic drugs, such as daunorubicin [109]. Preliminary data from our lab provide circumstantial confirmation of this result. To establish sensitivity to doxorubicin ${ }^{9}$, U937 and 5 other leukemia cell lines were treated with increasing doses of doxorubicin and assayed for cell viability (data not shown). While all cell lines tested were sensitive to doxorubicin treatment, U937 was among the most sensitive, evidenced by $100 \%$ decrease in cell viability at $1 \mu \mathrm{M}$. In order to determine the effect of GCS inhibition on sensitivity to doxorubicin, dose response assays in U937 cells were first performed to establish the $\mathrm{IC}_{50}$ of doxorubicin $(55 \mathrm{nM}), \operatorname{PDMP}^{10}(72 \mu \mathrm{M})$ and PPMP $(11 \mu \mathrm{M})$ (data not shown). U937 cells were treated with doxorubicin in a dose-response manner alone or in combination with the $\mathrm{IC}_{30}$ of PDMP or PPMP. Cells were also treated with increasing doses of PDMP or PPMP with addition of doxorubicin $\mathrm{IC}_{30}$. PDMP in combination with doxorubicin resulted in marked resistance to the drug, and vice versa (Fig. 7A-B). The same result was seen upon dose response treatment with PPMP, although in this case resistance was even more striking (Fig 7C-D).

As a note with respect to these results, it should be acknowledged that while the calculated $\mathrm{IC}_{30}$ of both PDMP and PPMP were used, in actuality the calculated inhibition was $5 \%$ and $50 \%$, respectively. These data are preliminary results, and will require optimization and duplication in order to confirm.

\section{Inhibitors Of Glycolysis and PPP Synergiz Ceramide:Glycosphingolipid Ratios}

e with $\mathrm{ABT}-263$ to Inc rease

Anti-apoptotic BCL-2 family proteins are up-regulated in many cancers, especially leukemias [118]. We have shown previously that that PDMP, an inhibitor of GCS activity, sensitizes U937

\footnotetext{
${ }^{9}$ Doxorubicin is a derivative of daunorubicin, both being anthracyclines with anti-tumor properties. Doxorubicin has a higher therapeutic index.

${ }^{10}$ PDMP: a well-established ceramide analog inhibitor of GCS; PPMP is a derivative of PDMP with a markedly higher potency
} 
cells to treatment with ABT-263, a small molecule inhibitor of anti-apoptotic BCL-2 family proteins Bcl-2, BCL-xL and Bcl-w [103]. To evaluate whether inhibition of the proposed metabolic pathways upstream of glycosphingolipid formation also synergize with ABT-263 in killing leukemia cells, we tested the combination of 2-DG or 6-AN with ABT-263 in U937 cells. Cells were treated in a dose-response manner for $48 \mathrm{~h}$, either with increasing doses of 2-DG and the $\mathrm{IC}_{30}$ of $\mathrm{ABT}-263$ or vice versa (Fig. 8A). The same treatment pattern was followed using 6AN and ABT-263 (Fig. 8B). The presence of 2-DG or 6-AN dramatically decreased the dose of ABT-263 required to induce cell death. The $\mathrm{IC}_{50}$ for ABT-263 alone was $5 \mu \mathrm{M}$, however upon addition of 2-DG decreased by 12.5 -fold to $0.4 \mu \mathrm{M}$. Similarly, the $\mathrm{IC}_{50}$ of ABT-263 decreased even more dramatically in combination with $6-\mathrm{AN}$, from $5 \mu \mathrm{M}$ to $0.15 \mu \mathrm{M}$, a 37-fold reduction. The same phenomenon was observed when ABT-263 was added at a constant dose to increasing doses of 2-DG or 6-AN, reducing the $\mathrm{IC}_{50}$ by 14 -fold and 18-fold, respectively.

If 2-DG and 6-AN blocked the pathways which provide the requisite substrates for GlcCer production, then treatment of cells with these inhibitors should cause a significant decrease in the total GlcCer levels. Ceramide, GlcCer and lactosylceramide levels were measured via HPLCMS/MS following 8-hour treatment with 2-DG, 6-AN and ABT-263 alone or in combination. Increases in intracellular ceramide are a hallmark of apoptotic cell induction [62, 64]. Indeed, following treatment with ABT-263, which induces cell death through induction of mitochondrialinduced apoptosis, ceramide levels significantly increased. Furthermore, upon addition of 2-DG or 6-AN, ceramide levels synergistically increased compared to ABT-263 alone. As expected, 2DG or 6-AN alone did not significantly increase ceramide levels, given that at low concentrations they inhibit cell growth rather than induce apoptosis [119]. Notably, however, 2-DG and 6-AN caused a dramatic drop in GlcCer levels by $45 \%$ and $23 \%$, respectively, a decrease further augmented by addition of ABT-263 (an additional 20\% and 40\%, respectively) (Fig. 9). The role of lactosylceramide in cell death is not as clear, however it is worth noting that treatment with 6AN, not 2-DG, decreased lactosylceramide levels, as well (Fig. 9). 
These data further support the hypothesis that both glycolysis and the PPP are instrumental in providing substrates for GlcCer formation. Furthermore, nutrient deprivation via metabolic inhibition synergizes with ABT-263 in inducing cell death via ceramide accumulation within the cell, data which is consistent with many other studies showing that metabolic inhibition of cancer cells primes for cell death induction via cytotoxic inhibitors $[53,54,120]$. 


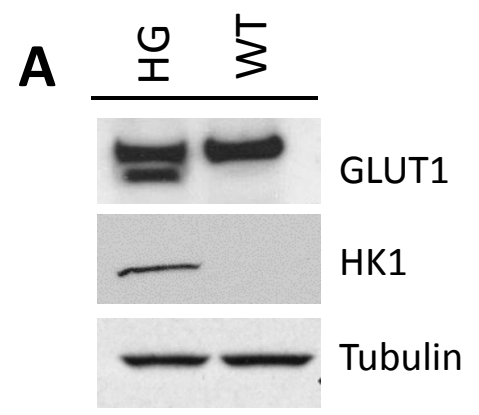

B
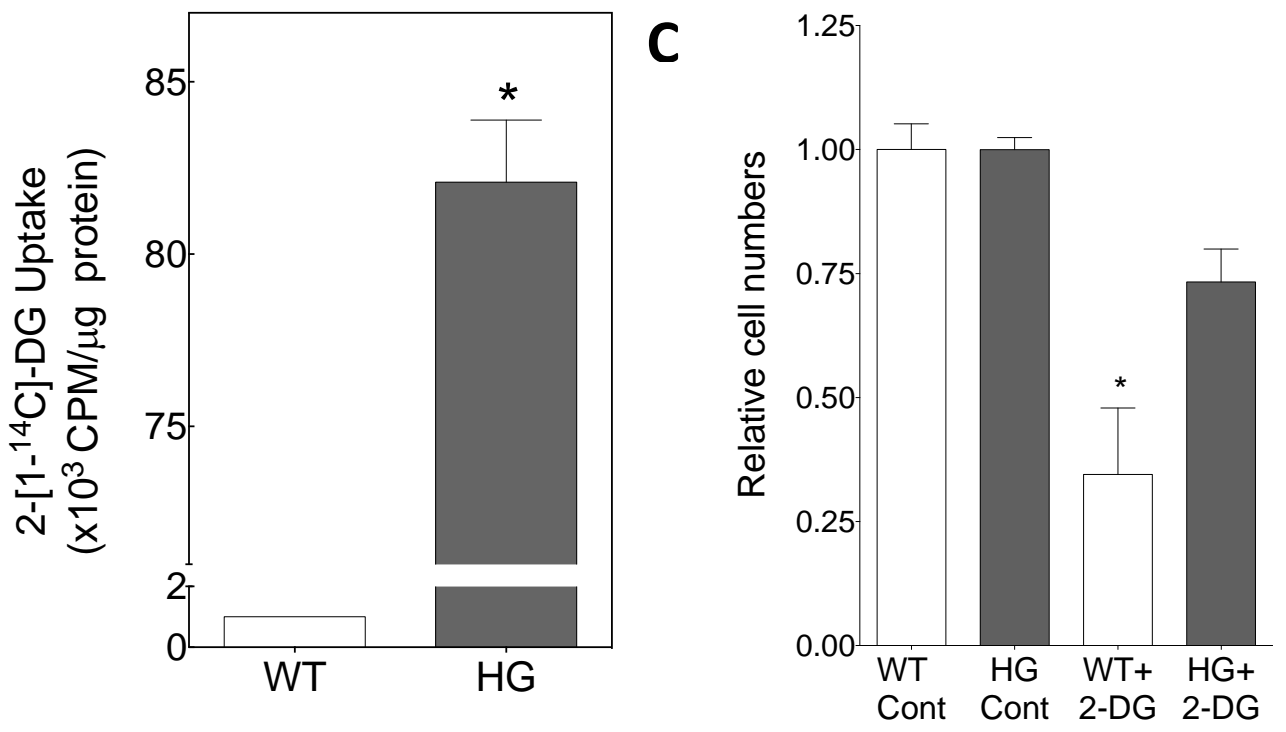

Figure 2: FL5.12 cells overexpressing GLUT1 and HK1 are highly glycolytic.

a) FL5.12 HG cells stably overexpress glycolytic enzymes GLUT1 and HK1. Overexpression of integral membrane protein GLUT1 and HK1 was confirmed by western blot. HK1 is not endogenously expressed in wild-type FL5.12 cells. b) FL5.12 WT and HG cells were grown in glucose-free media for one hour, incubated with 14C 2-Ddeoxy-glucose for one hour, then collected and counted by scintillation. FL5.12 HG cells took up significantly more glucose than their WT counterparts. d) FL5.12 cells were treated for 48 hours with $1 \mathrm{mM}$ 2-DG and cell viability was measured using Alamar Blue reduction. Graph B represents duplicate samples, $\mathrm{n}=2$. 

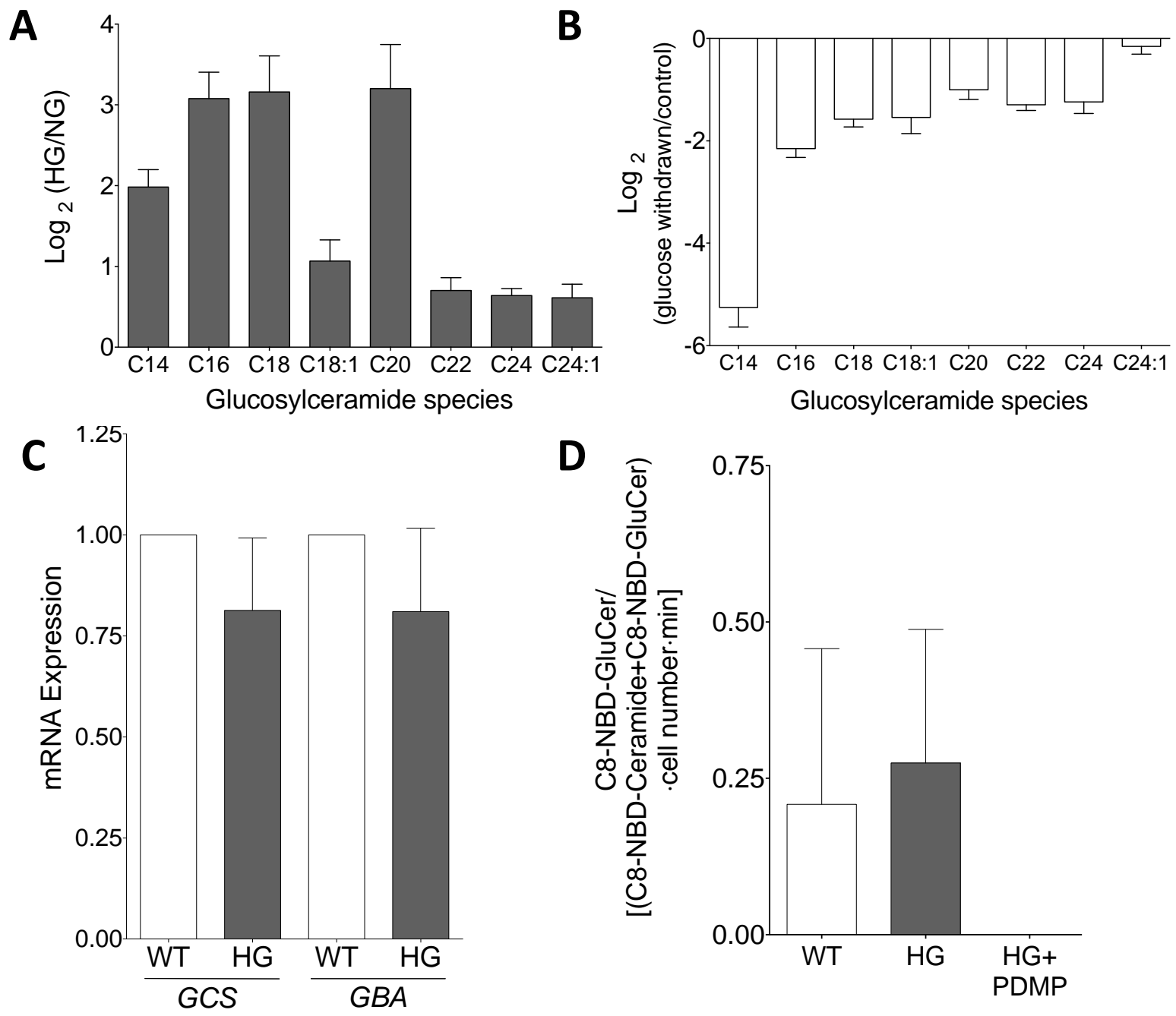

Figure 3: Glucosylceramide levels are elevated in a model of highly glycolytic cells.

a) Cellular lipids were harvested from FL5.12 cells growing in log phase. Glucosylceramide levels were determined by HPLC-MS/MS. HG levels were normalized to WT. b) FL5.12 wild-type cells were glucosedeprived for 18 hours and the total amount of cellular glucosylceramides was determined by HPLCMS/MS. c) FL5.12 cells were grown for 24 hours in log phase with complete media then analyzed for expression of GCS and GBA via qPCR. WT expression was set to 1.0 and HG expression was normalized to wild-type. GCS and GBA expression decreased compared to wilt-type cells. d) GCS activity was measured in FL5.12 wild-type and HG cells. Cells were grown in complete media for 2 hours and then analyzed for GCS activity via addition of NBD-ceramide and separation on TLC. Graphs B and D represent duplicate samples, $\mathrm{n}=2$. 

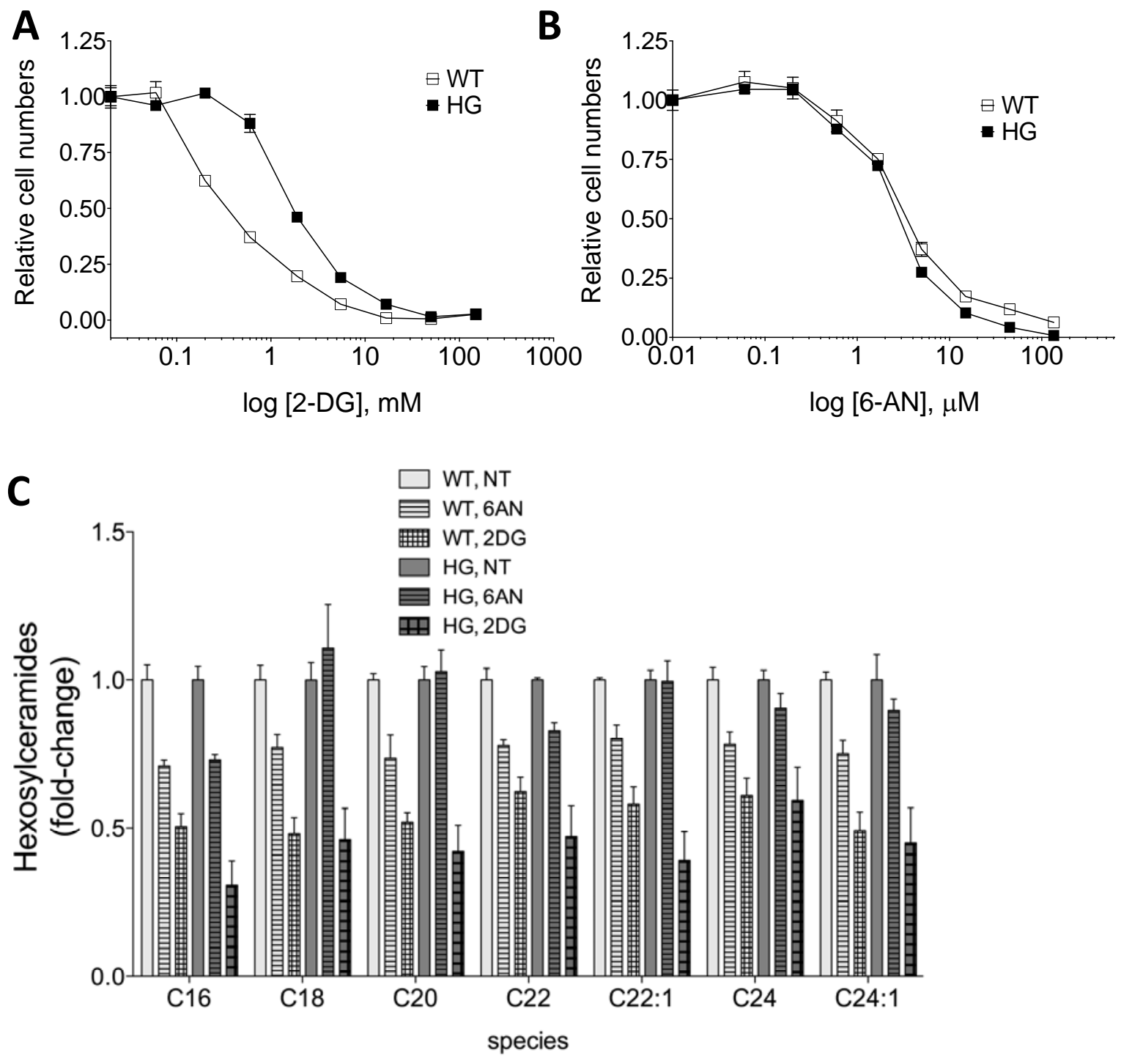

Figure 4: Inhibition of FL5.12 cells with metabolic inhibitors depletes GSLs.

Cells were treated for 48 hours with a) 2-DG $(0.06-150 \mathrm{mM})$ or b) 6-AN $(0.06-135 \mu \mathrm{M})$ then measured for cell viability via AlamarBlue reduction. HG cells are more resistant to treatment with HK-1 competitive inhibitor 2-DG vs wild-type cells $\left(\mathrm{IC}_{50}=0.33 \mathrm{mM}\right.$ vs $1.7 \mathrm{mM}$ for wild-type and $\mathrm{HG}$, respectively, at 48 hours). No significant different was seen in response to 6-AN treatment $\left(\mathrm{IC}_{50}=2.9 \mu \mathrm{M}\right.$ vs $2.6 \mu \mathrm{M}$ for WT and $\mathrm{HG}$, respectively). c) FL5.12 cells were treated with 2-DG or 6-AN at their respective $\mathrm{IC}_{50}$ for 8 hours. Total hexosylceramide levels were determined via HPLC-MS/MS. Long-chain ceramides (C16-20) and very long chain ceramides (C22+) are shown. Lipids levels were normalized to viable cell number. 

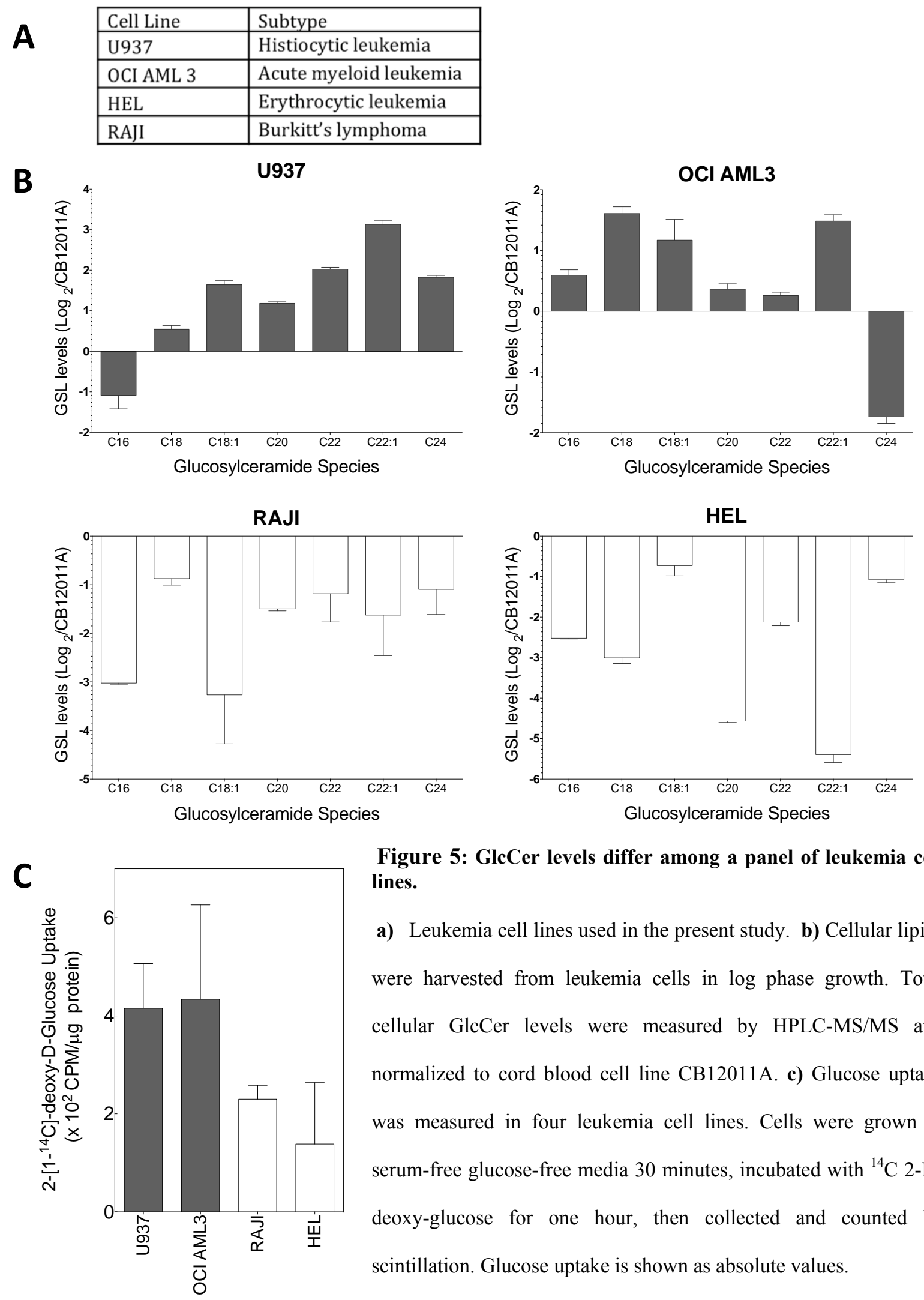

Figure 5: GlcCer levels differ among a panel of leukemia cell lines.

a) Leukemia cell lines used in the present study. b) Cellular lipids were harvested from leukemia cells in log phase growth. Total cellular GlcCer levels were measured by HPLC-MS/MS and normalized to cord blood cell line CB12011A. c) Glucose uptake was measured in four leukemia cell lines. Cells were grown in serum-free glucose-free media 30 minutes, incubated with ${ }^{14} \mathrm{C} 2$-Ddeoxy-glucose for one hour, then collected and counted by scintillation. Glucose uptake is shown as absolute values. 

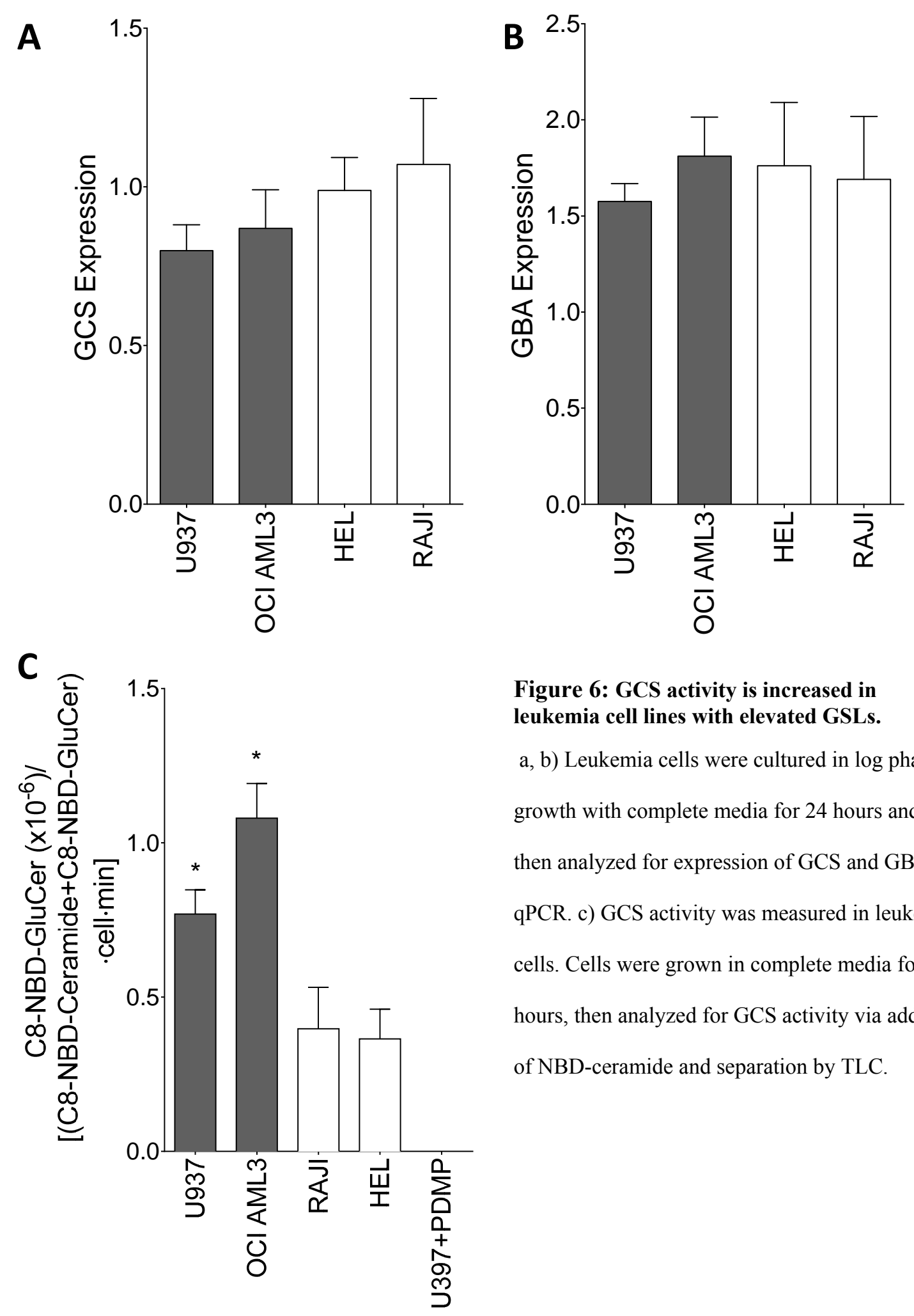

Figure 6: GCS activity is increased in leukemia cell lines with elevated GSLs.
a, b) Leukemia cells were cultured in log phase
growth with complete media for 24 hours and
then analyzed for expression of GCS and GBA by
qPCR. c) GCS activity was measured in leukemia
cells. Cells were grown in complete media for 2
hours, then analyzed for GCS activity via addition
of NBD-ceramide and separation by TLC. 

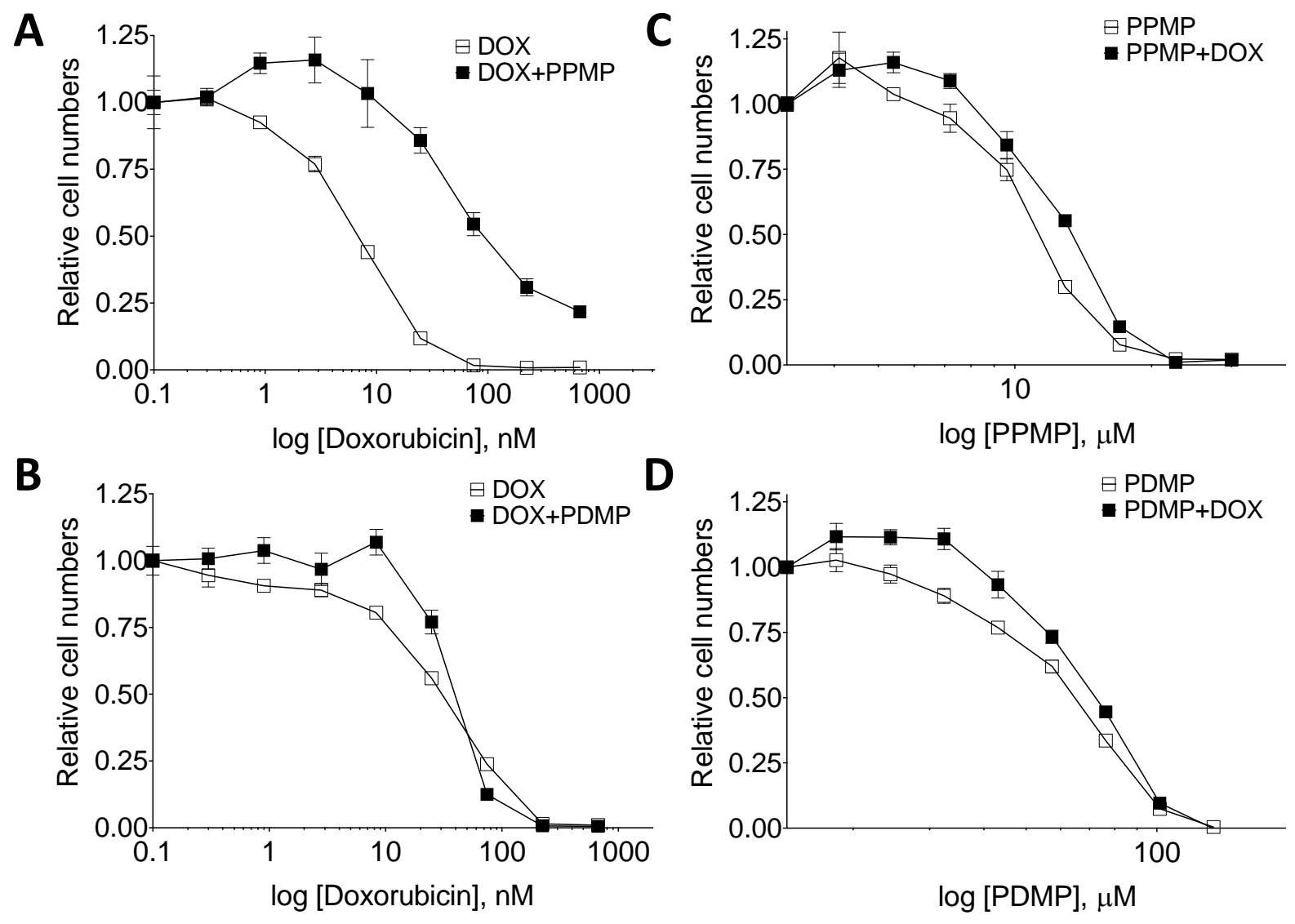

Figure 7: Preincubation with GCS Inhibitors confers resistance to doxorubicin in leukemia cells.

U937 cells were treated with a) increasing doses of doxorubicin $(0.3-670 \mathrm{nM})$ alone or in combination with PPMP IC $\operatorname{IC}_{30}(11 \mu \mathrm{M})$; b) increasing doses of PPMP $(4.1-30 \mu \mathrm{M})$ in combination doxorubicin $\mathrm{IC}_{30}(21 \mathrm{nM})$; c) increasing doses of doxorubicin $(0.3-670 \mathrm{nM})$ alone or in combination with PDMP $\operatorname{IC}_{30}(72 \mu \mathrm{M})$; d) increasing doses of PDMP (18.3-135 $\mu \mathrm{M})$ alone or in combination with doxorubicin $\mathrm{IC}_{30}(21 \mathrm{nM})$. Cell viability was measured 48 hours after treatment with via Alamar Blue reduction. 

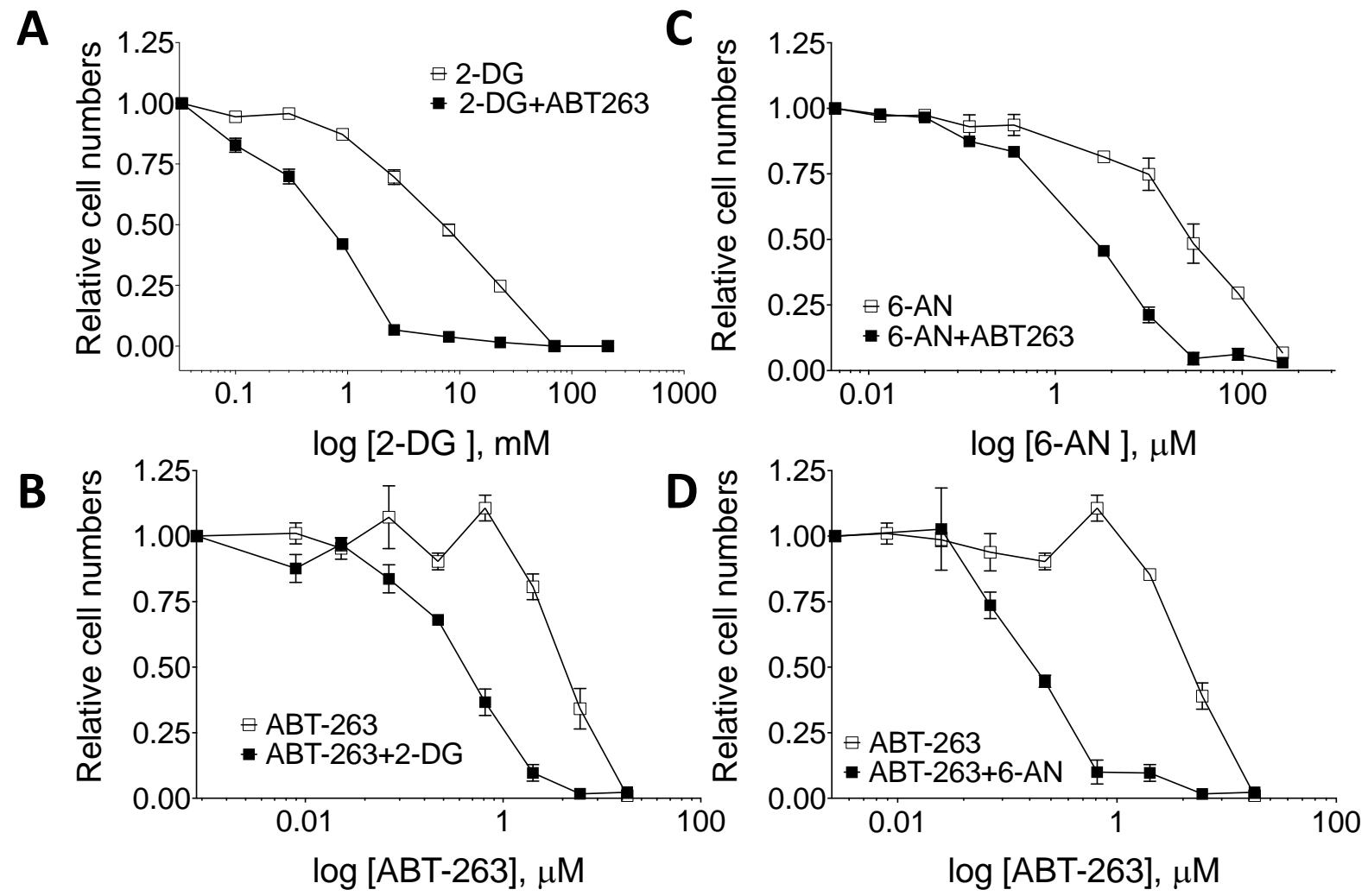

Figure 8: Inhibitors of glycolytic metabolism and the pentose phosphate pathway synergize with an inhibitor of anti-apoptotic BCL2 proteins.

a,b) U937 cells were incubated for 48 hours with a) increasing doses of 2-DG plus either vehicle or ABT$263 \mathrm{IC}_{30}(5 \mu \mathrm{M})$ or $\left.\mathrm{b}\right)$ increasing doses of ABT-263 plus vehicle or the $\mathrm{IC}_{30}$ of 2-DG $(1.7 \mathrm{mM})$ for 48 hours. The relative number of viable cells was determined using reduction of AlamarBlue reagent. c,d) U937 cells were incubated for 48 hours with c) increasing doses of 6-AN plus vehicle or $\mathrm{IC}_{30}(5 \mu \mathrm{M})$ of ABT-263 or d) increasing doses of ABT-263 plus vehicle or the $\mathrm{IC}_{30}$ of 6-AN for 48 hours. Cell viability was determined using reduction of AlamarBlue reagent. Doses: 2-DG: $33 \mu \mathrm{M}$ to $170 \mathrm{mM}$; $6-\mathrm{AN}$ : $13.3 \mathrm{nM}$ to $170 \mathrm{uM}$; ABT-263: $2.7 \mathrm{nM}$ to $18 \mathrm{uM}$. 

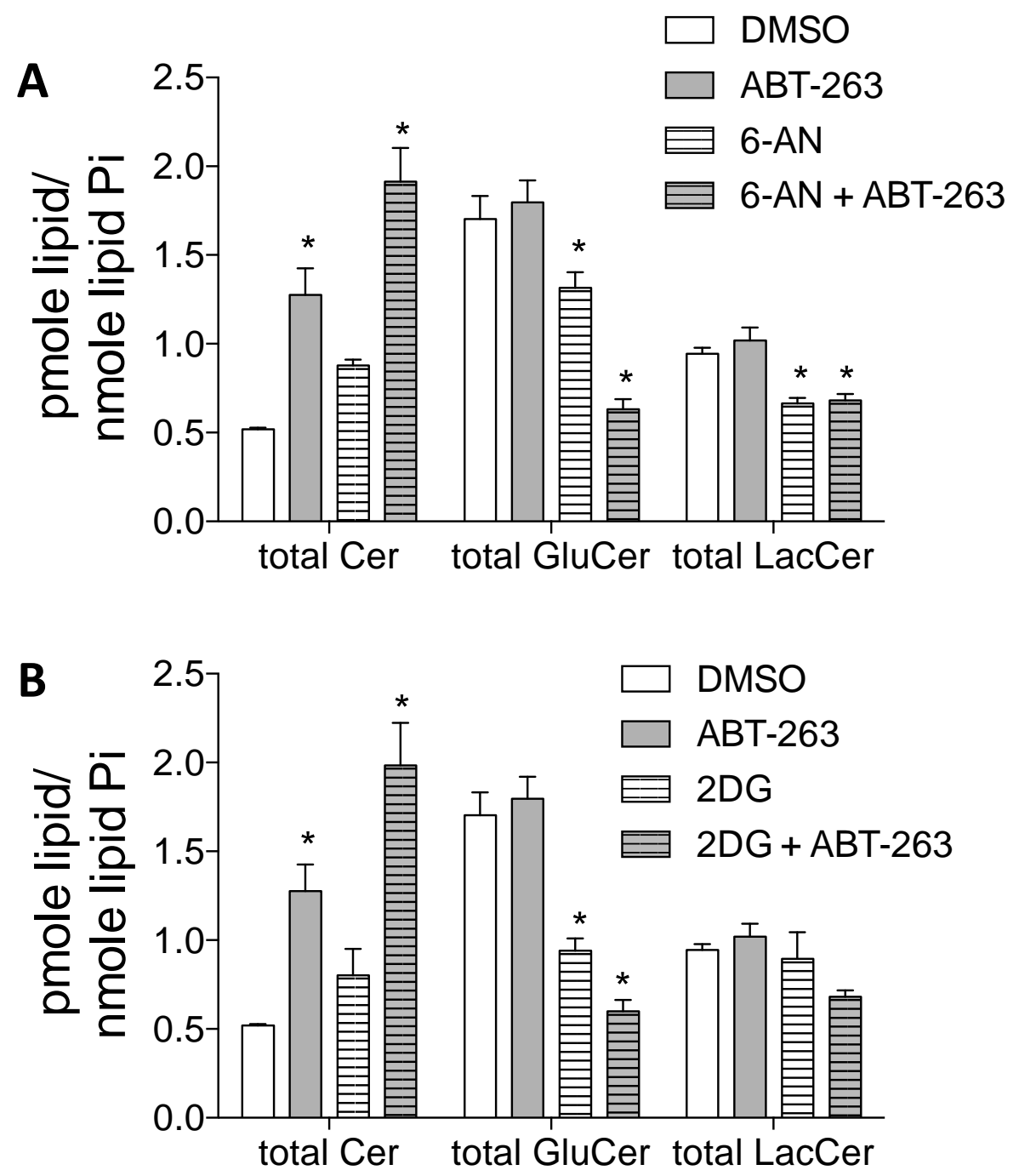

Figure 9: Inhibitors of glycolytic metabolism and the pentose phosphate pathway synergize with an inhibitor of anti-apoptotic BCL2 proteins to increase ceramide:glycosphingolipid ratios.

a) U937 cells were treated with vehicle (DMSO), ABT-263 $\mathrm{IC}_{30}(5 \mu \mathrm{M}), 6-\mathrm{AN} \mathrm{IC}_{30}(1.7 \mu \mathrm{M})$, or the combination of 6-AN and ABT-263 at their respective $\mathrm{IC}_{30} 8$ hours. Cells were harvested and lipids were analyzed via HPLC/MS-MS. b) U937 cells were treated vehicle (DMSO), ABT-263 IC $_{30}(5 \mu \mathrm{M}), 2-\mathrm{DG}$ $\mathrm{IC}_{30}(5 \mathrm{mM})$, or the combination of 2-DG and ABT-263 at their respective $\mathrm{IC}_{30}$. Cells were harvested and lipids were analyzed via HPLC/MS-MS. 


\section{DISCUSSION}

There exists a limited amount of data linking glucose availability in cells to production of glycosphingolipids (GSLs), the seminal work being performed by the Shayman Group [38, 39] in rat models of DM1. Furthermore, this phenomenon has never been shown outside of a metabolic disease state. In the present study we have shown that there exists a definitive link between glucose availability and GSL formation, independent of aberrant intracellular signaling pathways of cancer cells or the influence of the extracellular environment present in disease states. Glucose transporter 1 (GLUT1) and Hexokinase II (HK2) are often overexpressed in response to oncogenic signaling pathways to support the highly glycolytic nature of the cancer cell [121, 122]. Our model of highly glycolytic cells, FL5.12 HG, overexpressed the same enzymes in a non-transformed hematopoietic cell line (Fig. 2A), which increased glucose availability (Fig. 2B) and significantly elevated GlcCer levels (Fig. 3A). On the other hand, glucose withdrawal in wild-type FL5.12 cells correspondingly decreased GlcCer below baseline levels (Fig. 3B), thus supporting our hypothesis that glucose availability in and of itself can directly influence glycosphingolipid levels. We found that this is primarily a substrate-driven process, given that neither expression nor activity of GCS, the enzyme responsible for GlcCer formation, was significantly altered between the two cell lines.

It is taken as canon in cancer biology that a hallmark of neoplastic cells is reliance on aerobic glycolysis over oxidative phosphorylation. In order to support the increased utilization of aerobic glycolysis for production of ATP, many cancers, solid tumors and blood cancers inclusive, also take up elevated amounts of glucose $[3,6,9]$. A growing body of evidence that suggests one of the main advantages of and reliance on aerobic glycolysis is the production of intermediates for 
shunting into bioenergetic and anaplerotic pathways. Production of such substrates serves to support the requisite increase in biomass of the rapidly dividing cell. For example, increased flux into the PPP results in increased nucleotide formation via production of ribose-5-phosphate. In keeping the "biomass hypothesis", we tested whether inhibition of two bioenergetic pathways, glycolysis and the PPP, would result in decreased GSL levels. Indeed, treatment with 2-DG and 6-AN decreased hexosylceramide levels in both cell lines (Fig. 4C). These results suggested that pathways downstream of glucose uptake may provide the requisite substrates for production of hexosylceramides, namely GlcCer. Therefore, increased glucose uptake elevates flux into these pathways and subsequently levels of these intermediates, thereby increasing GSL levels.

Leukemia and lymphoma are umbrella classifications for complex and heterogeneous groups of bone marrow- and lymphatic-derived malignancies, respectively, each with its own unique aberrations in cellular signaling and metabolic profiles. As such, we chose to study the relationship between glucose metabolism and GSL levels irrespective of genetic background in a panel of leukemia and lymphoma cell lines (U937, OCI AML3, RAJI, HEL) (Fig. 5A). Given that cancer cells are already highly glycolytic in nature, it is not surprising that a significant difference in glucose uptake was not observed between the leukemia cell lines (Fig. 5C), or that GlcCer levels are not entirely dependent on its uptake, although from the data it could be inferred that differential uptake may play a role. On the other hand, we found that GCS activity is significantly increased in cell lines with elevated GlcCer levels. This is in contrast to FL5.12 HG cells, where GlcCer levels directly correlated to glucose uptake, without significantly altering GCS expression or activity. Overall, these data indicate that other mechanisms may be at play in transformed cells in addition to regulation of substrate uptake and GCS enzyme expression, which may include regulation of substrate activity. As the following data would indicate, this may be related to preferential shunting of glucose into pathways essential for GlcCer and GSL production in cell lines with elevated GSL levels. 
Prior data in our lab showed that PDMP, a ceramide analogue inhibitor of GCS, synergizes with ABT-263, an inhibitor of pro-apoptotic BCL-2 like proteins, in inducing apoptosis in leukemia cells [103]. In the present study we showed that both 2-DG and 6-AN, inhibitors of glycolysis and the PPP, respectively, also synergized with ABT-263 in U937 cells. Furthermore, treatment with 2-DG and 6-AN led to a significant reduction in GlcCer levels, which were further decreased upon co-treatment with ABT-263. ABT-263 alone increased the pro-apoptotic lipid ceramide, an effect which was significantly augmented upon addition of 2-DG or 6-AN. Notably, neither 2-DG nor 6-AN increased ceramide levels significantly on their own, indicating that these two metabolic inhibitors act synergistically to augment the effect of ABT-263.

On the basis of the observations that 1) increased glucose uptake leads to increased GSL levels and 2) inhibition of metabolic pathways such as glycolysis and the pentose phosphate pathway reduce GSL levels, we hypothesize that in addition to producing intermediates for biosynthetic reactions which fuel the highly proliferative state of cancer cells, formation of these substrates also serves to increase the production of glycosphingolipids via GCS. An overview of the proposed mechanism is provided in Fig. 11. Briefly, through shunting into the PPP, glucose provides intermediates such as ribose-5-phosphate for synthesis of nucleotides such as UTP. Increased glucose uptake also leads to increased flux into glycogen synthesis [123], which forms UDP-glucose from UTP and glucose. Increase in glucose availability has been previously shown to increase intracellular UDP-glucose levels in the kidney in rat models of DM1 [112, 124], an increase which was later shown to elevate GSL levels [38, 39]. In this work, it was hypothesized that UDP-glucose is utilized by GCS to form GlcCer through its addition to ceramide in diabetic conditions within the kidney (Fig. 10). Accordingly, we hypothesize that in highly glycolytic cells, such as cancers, one role of increased glucose uptake is to form UDP-glucose for use by GCS to form GlcCer, in an attempt to deplete ceramide levels and evade apoptosis. It is also plausible that other pathways could play a role in GlcCer formation, such as generation of NADPH for use as a cofactor in de novo ceramide synthesis. The PPP has also been implicated 
recently in the transformed phenotype of cancer cells [20]. Furthermore, glucose-derived pyruvate is utilized by the TCA cycle in transformed cells for production of anaplerotic intermediates such as citrate for fatty acid synthesis [4], a mechanism which would support an increase in overall production sphingolipids, including GlcCer. Future work in this area will focus on the exact substrates elevated in cancer cells in response to increased glucose availability for GlcCer formation, although we speculate that these will include: UDP-glucose, palmitoyl-COA, fatty acids, and NADPH.

Taken together, down what therapeutic road do the present results lead us? Current standard of care in many cancers focuses on targeting the highly proliferative phenotype of cancer cells with genotoxic drugs such as platinums, anthracyclines, and pyrimidine analogs, among others. However, these therapies are limited by the near inevitability of acquired resistance and metastatic relapse [125], often of a more aggressive phenotype and association with poor patient outcome [126-129]. By utilizing therapeutics which do not rely on targeting rapidly dividing cells, but instead which target other intrinsic properties of malignant cells, it may be possible to avoid development of resistance or disease relapse. Such is the theory behind the combination of 2-DG and ABT-263, in that this treatment targets two independent weaknesses that are nearly ubiquitous among cancer cells: dependence on aerobic glycolysis and overexpression/dependence on an intracellular target. It has been shown that the anti-apoptotic subfamily of BCL-2 proteins are overexpressed in a large amount of leukemia subtypes $[118,130]$. The combinatory therapy of 2-DG and ABT-263 has already proven effective in vitro and in vivo in many tumor-based malignancies [131], and we have now shown in the present study that this combination of therapeutics could also serve as an effective treatment option in leukemias. Furthermore, it has been shown that altered ganglioside expression in cancers $[50,74,76,132]$, particularly upregulation of certain species such as GM3, is associated with a more aggressive and malignant phenotype in some cancers [50], such as melanoma [71, 133, 134]. This increased GM3 expression has been shown to both increase resistance and negatively regulate apoptosis through 
a Bcl-2-mediated mechanism [135]. Accordingly, inhibition of GCS in a drug-resistant cell line both reversed drug resistance and increase sensitivity to apoptosis through decreasing Bcl-2 expression [136]. Given this association and the data presented in the current study, it would follow that treatment with the BCL2 proapoptotic family inhibitor ABT-263 may also function to abate ganglioside-mediated resistance to treatment and apoptosis.

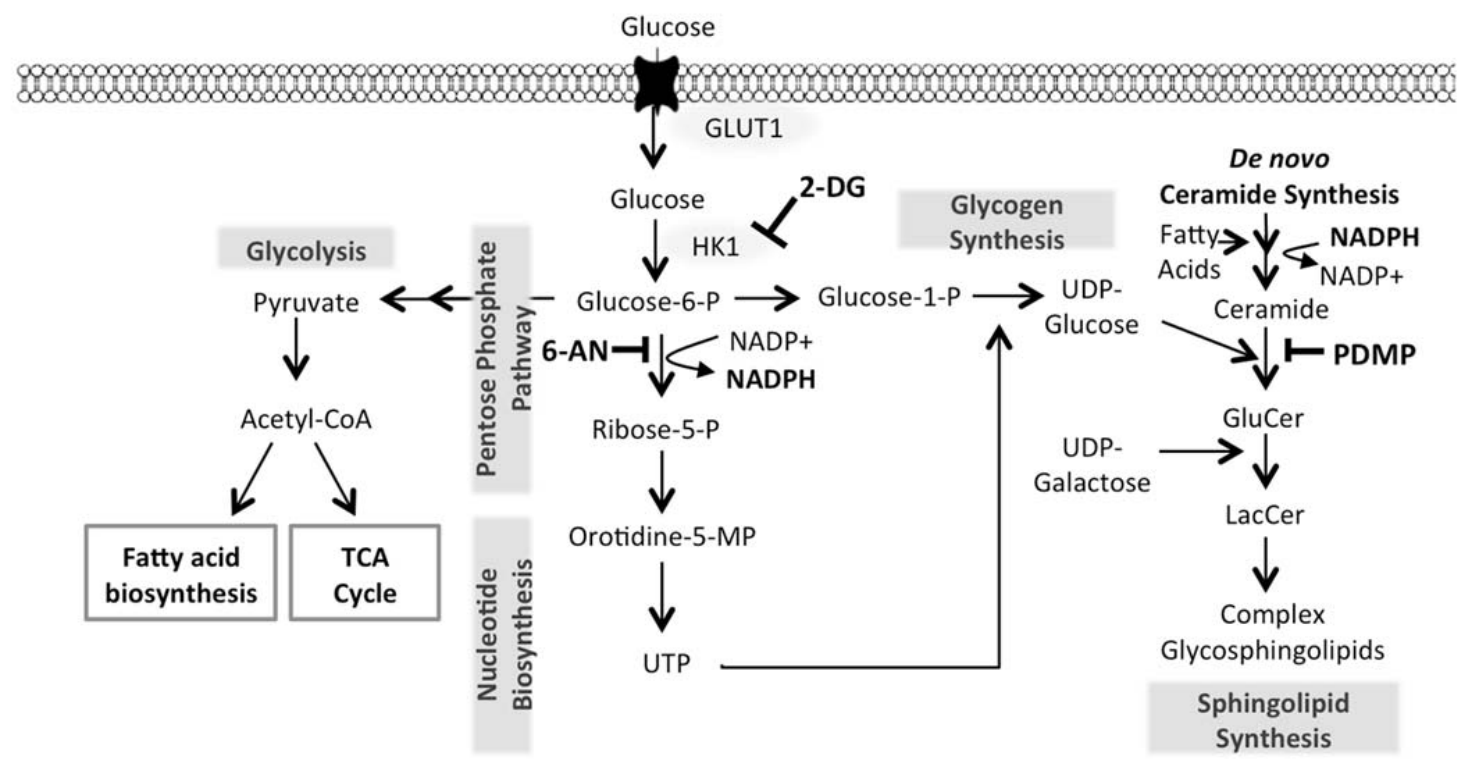

Figure 10: Proposed mechanism of glycosphingolipid production via formation of substrates via glycolysis, the PPP and glycogenesis in highly glycolytic cells.

Certain leukemia cells take up elevated levels of glucose, leading to increased flux through glycolysis and into the pentose phosphate pathway, glycogen synthesis, nucleotide biosynthesis and the TCA cycle. We hypothesize that increased flux into these pathways leads to the production of the rate-limiting substrates necessary for glycosphingolipid formation, namely, fatty acyl CoA, UDP-glucose, and NADPH. 


\section{CONCLUSIONS}

\section{Future Directions}

The present work demonstrates a clear relationship between glycolytic metabolism and (glyco)sphingolipid biosynthesis in the context of elevated glucose availability. Future work would be based on strengthening this relationship and further characterizing its implication in cancer therapeutics. Data presented herein led us to formulate the hypothesis that increased glucose uptake results in elevated flux through glycolysis and the PPP, thereby forming the requisite substrates for GSL synthesis. Measurement of the metabolites implicated in GSL formation would be instrumental in supporting this hypothesis. The ensuing paragraphs will outline proposed experiments for detection of substrate uptake, metabolite detection and subsequent incorporation into GSLs. Unless otherwise indicated, "highly glycolytic cells" will be collectively used to indicate a general phenotype of increased glucose availability in both transformed and non-transformed cell types.

In addition to being a critical cellular antioxidant, NADPH plays a vital role as a reducing agent in many biosynthetic pathways. We proposed that NADPH produced by increased flux through the PPP in highly glycolytic cells aids in formation of GSLs, as it is used in both in fatty acid synthesis and in de novo ceramide synthesis. Simple measurement of NADPH could be performed using commercially available kits to observe the effect of glucose availability, as well as the effect of metabolic inhibitors used herein, such as 2-DG, 6-AN and PDMP/PPMP, on NADPH levels. If more detailed analysis of NADPH were required, a recently improved method for NADPH redox detection using deuterium for isotope labeling has been published [137]. This

method utilizes ${ }^{2} \mathrm{H}$ labeling and subsequent quantification via mass spectrometry or NMR, 
allowing for distinction between NADH and NADPH production. Additionally, contribution of different subcellular locations to NADPH production can be determined using cellular fractionation techniques preceding quantification. This would be of importance in establishing whether putative increased NADPH in the ER, the site of de novo ceramide synthesis, plays a role in increased GSL formation. It is worth nothing that studies have suggested elevated glutamine metabolism may play as critical a role as the PPP in producing NADPH in neoplastic cells, thus it may be beneficial to look at players in this pathway as well using similar mechanisms [4].

UDP-Glucose and ceramide are utilized by glucosylceramide synthase to produce glucosylceramide. Data from animal models of DM1 have shown that UDP-glucose is elevated in response to increased glucose uptake $[38,39]$. We hypothesized that increased glucose flux in highly glycolytic cells results in increased flux into glycogen synthesis, thereby increasing the formation of the requisite UDP-glucose. This phenomenon would be expected to occur more readily in neoplastic cells, which benefit from increased glycogen stores during times of stress or starvation [29, 30]. The enzyme responsible for UDP-glucose production is UDP-glucose pyrophosphorylase (or glucose-1-phosphate uridyltransferase) (UGP), which catalyzes the reversible synthesis of UDP-glucose from glucose-1-phosphate and UTP, releasing a pyrophosphate group. To determine the contribution of this pathway to GSL in highly glycolytic cells, expression and levels of UGP could be measured in both HG and leukemia cells to determine the effect of elevated glucose availability. I would also propose inhibition of UGP to emulate "normal" levels, both pharmacologically and genetically, to determine the effect on GSL levels. I suggest in both methods only partial reduction in UGP activity, seeing as UDP-glucose is necessary for a myriad of cellular functions and therefore its complete inhibition may produce exaggerated and off-target effects. Conversely, overexpression of the enzyme would further confirm (or deny) the contribution of UGP to GSL production. If our hypothesis were correct, inhibition of UGP would deplete GSL levels, while its overexpression would elevate them. 
Increased fatty acid synthesis to support the requisite increase in biomass demanded by the neoplastic cell has also been described as a component of deregulated cancer cell metabolism. Palmitoyl-CoA ${ }^{11}$ is utilized in the first step of de novo ceramide synthesis and is thus critical to sphingolipid metabolism and GSL formation. I propose using radiolabeled ${ }^{13} \mathrm{C}$-glucose to examine its incorporation into palmitate and subsequently into sphingolipids and GSLs. Following incubation with the radiolabeled substrate, quantification would be performed using mass spectrometry or NMR.

In addition to elucidating the role of individual metabolites in GSL formation, I also propose further confirmation of the role of individual pathways (i.e. glycolysis, the PPP, glycogen synthesis) in the production of GSLs in highly glycolytic cells. This would be performed through genetic inhibition and overexpression of the rate-limiting enzymes responsible for control of these pathways: hexokinase (glycolysis), glucose-6-phosphate dehydrogenase (PPP) and glycogen synthesis (glycogenesis). As previously discussed, I would suggest the use of partial knockdown via RNAi in order to elicit more physiologically-relevant effects and to avoid the off target effects of complete ablation of a metabolic pathway.

Some studies have suggested that the role of GCS inhibitors in sensitizing to cytotoxic and metabolic drugs is actually attributed to their action on p-glycoprotein, rather than GCS [98, 107]. As such, I would also suggest use of more "specific" GCS inhibitors (i.e. of the imino sugar subclass) to confirm the results attained herein and therein, so that future experiments can be properly compared and performed.

Furthermore, future work would further explore the hypothesis that sphingolipid metabolism can play a paradoxical role in drug resistance under certain conditions. Namely, evidence has suggested that GCS inhibitors PDMP and PPMP play a cytoprotective role in combination with daunorubicin when used at a sublethal doses [109], confirmed by preliminary data in our lab in

\footnotetext{
${ }^{11}$ Palmitoyl-CoA: the CoA-charged version of palmitic acid, the first fatty acid produced by fatty acid synthesis and most common fatty acid in mammals
} 
the present study. Namely, we would aim to determine if 1) data gathered in additional cancer cell models (i.e. adherent vs non-adherent, given the role of cell-surface GSLs in adhesion) would recapitulate the cytoprotective effect at sublethal doses previously published and herein, and 2) the same cytoprotective effect would occur in response to treatment with lethal doses $\left(\mathrm{IC}_{30}\right)$ of PDMP/PPMP in combination with doxorubicin. If data suggest that sublethal doses are cytoprotective and lethal doses synergistic/additive/null effect, studies would proceed in the direction of investigating the molecular and metabolic basis underlying this effect. One hypothesis could incorporate the effect of GCS inhibition on drug efflux and the cytoprotective nature of p-glycoprotein. Briefly, it has been shown that p-glycoprotein is downregulated in response to GCS inhibition [96], and upregulated in response to GCS overexpression [95]. Intuitively, depletion of GlcCer, a p-gp substrate, via GCS inhibition would lead to compensatory upregulation of GCS to maintain GSL homeostasis. Given the suggested relationship between GCS and p-gp, this could consequently result in increased p-gp levels and subsequent drug efflux.

While cancer cell models are efficient for elucidation of biochemical pathways at the basic science level, they risk acquiring further mutations and differential phenotypes in addition to the original cancer. As such, further investigation of this phenomenon in a mouse model utilizing similar methods as described above (i.e. pharmacological and genetic inhibition of key metabolic enzymes, manipulation of glucose uptake in specific subsets of cells, etc.) would be critical in providing support for our hypothesis. Pulling from the in vitro studies, multiple facets of cancer cell metabolism and inhibition thereof will be addressed. This work would then move into analysis of patient-derived samples. Cancers should include hematological and solid tumor cancers of a variety of classes to observe if the phenotype is consistent across the board, in relation to the adherent nature of the cell. This is a critical consideration given the key role of GSLs in cell-cell adhesion, migration and metastasis. A panel of diverse neoplasms will allow comparison of our favorite metabolic pathways in the context of markedly different molecular aberrations. Such is the main argument for personalized medicine and clinical characterization of 
the molecular and metabolic "traits" of cancer cells. I propose analyzing glucose uptake in the same manner as the present study, followed by measurement of pertinent sphingolipid and GSL species. Given that glutamine metabolism may also play a role in these cells, I would also suggest performing glutamine uptake assays, as well. The aforementioned rate-limiting enzymes should be analyzed for mRNA expression and protein levels via qPCR and western blot, respectively. Finally, synergism assays as described herein, i.e. PDMP/PPMP in combination with the respective cytotoxic drug, should be performed. All experiments should be compared to clinical scores: stage/score, aggressiveness, responsiveness to therapy, metastatic or non-malignant, etc.

Finally, we would like to more fully characterize the role of 2-DG and the glycolytic pathway in decreasing GSL levels, and if the decrease in GSL levels is a prerequisite for the synergistic effect observed in the combinatory treatment of 2-DG and 6-AN with ABT-263. In order to reconstitute GSL levels in the cell, we propose inhibiting GBA, the enzyme responsible for degradation of GlcCer, which would result in increased GlcCer and upstream GSLs.

As a parting note, the future method of lipid quantification is worth discussing in brief. HPLC-MS/MS is a very sensitive method for sphingolipid detection, given that in addition to quantitating overall lipid levels, it has the ability to also differentiate by fatty acid chain length. However, it can be extremely costly if outsourced, as is often the case. If a more cost-effective alternative were needed, it would be possible to measure the cause-effect relationship of inhibiting GSL production using flow cytometric analysis directed towards specific GSL molecules, such as GM1 or GD3 [138]. Furthermore, less sensitive methods such as TLC, used herein, are acceptable methods in combination with labeled substrates such as ${ }^{13} \mathrm{C}$-glucose.

\section{Caveats/Weaknesses}

The caveats of the present study are ones which should be addressed and accepted in all works which aim to target aberrant signaling and/or metabolic pathways as a means of treatment. Cancer cells are complex, multi-faceted, transformed versions of normal cells. No aberration 
exists in and of itself, and rarely is any alteration in and of itself the sole reason for the transformation from normal to neoplastic. Signaling pathways are inherently interconnected and we must treat them as such; inhibition of one pathway will most likely result in eventual upregulation of another pathway; inhibition of one aspect of metabolism may result in increased reliance on another aspect of metabolism to support cancer growth. While glucose availability may impact GSL formation through the aforementioned pathways, the function of increased glucose uptake and utilization is by no means solely for production of GSLs, just as elevation of GSLs is most likely not the crippling Achilles heel of cancer. The goal of chemotherapeutics should be in simultaneously targeting multiple weaknesses of cancer cells in order to kill as many cells as possible in an attempt to avoid the inevitable resistance that will occur with single treatments.

Furthermore, the present study discusses the use of metabolic inhibitors to target cells addicted to aerobic glycolysis. This approach will indiscriminately target all rapidly dividing cells, and thus be prone to the side effects of established chemotherapies. It has been suggested a "therapeutic window" exists for such treatments [51], although more work needs to be conducted to approve or disapprove this notion. It is possible that as nanotechnology advances, treatments may be targeted directly towards tumors using membrane-associated antigens, and thus would avoid the aforementioned off-target effects. 


\section{REFERENCES}

1. Mukherjee, S., The emperor of all maladies : a biography of cancer. 2010, New York: Scribner.

2. Galluzzi, L., et al., Metabolic targets for cancer therapy. Nat Rev Drug Discov, 2013. 12(11): p. 829-46.

3. Lunt, S.Y. and M.G. Vander Heiden, Aerobic Glycolysis: Meeting the Metabolic Requirements of Cell Proliferation. Annual Review of Cell and Developmental Biology, 2011. 27(1): p. 441-464.

4. DeBerardinis, R.J., et al., Beyond aerobic glycolysis: transformed cells can engage in glutamine metabolism that exceeds the requirement for protein and nucleotide synthesis. Proc Natl Acad Sci U S A, 2007. 104(49): p. 19345-50.

5. DeBerardinis, R.J., et al., The biology of cancer: metabolic reprogramming fuels cell growth and proliferation. Cell Metab, 2008. 7(1): p. 11-20.

6. Hsu, P.P. and D.M. Sabatini, Cancer Cell Metabolism: Warburg and Beyond. Cell, 2008. 134(5): p. 703-707.

7. Dang, C.V., Links between metabolism and cancer. Genes Dev, 2012. 26(9): p. 877-90.

8. Vander Heiden, M.G., L.C. Cantley, and C.B. Thompson, Understanding the Warburg effect: the metabolic requirements of cell proliferation. Science, 2009. 324(5930): p. 1029-33.

9. Warburg, O., On the origin of cancer cells. Science (New York, N.Y.), 1956. 123(3191): p. 309-314.

10. Zhuang, L., et al., Cholesterol targeting alters lipid raft composition and cell survival in prostate cancer cells and xenografts. J Clin Invest, 2005. 115(4): p. 959-68.

11. Ma, L., et al., Lovastatin induces multiple stress pathways including LKB1/AMPK activation that regulate its cytotoxic effects in squamous cell carcinoma cells. PLoS One, 2012. 7(9): p. e46055.

12. Gogvadze, V., B. Zhivotovsky, and S. Orrenius, The Warburg effect and mitochondrial stability in cancer cells. Mol Aspects Med, 2010. 31(1): p. 60-74.

13. Khandekar, M.J., P. Cohen, and B.M. Spiegelman, Molecular mechanisms of cancer development in obesity. Nat Rev Cancer, 2011. 11(12): p. 886-95. 
14. Pollak, M., The insulin and insulin-like growth factor receptor family in neoplasia: an update. Nat Rev Cancer, 2012. 12(3): p. 159-69.

15. Fendt, S.M., et al., Metformin decreases glucose oxidation and increases the dependency of prostate cancer cells on reductive glutamine metabolism. Cancer Res, 2013. 73(14): p. 4429-38.

16. Hirsch, H.A., D. Iliopoulos, and K. Struhl, Metformin inhibits the inflammatory response associated with cellular transformation and cancer stem cell growth. Proc Natl Acad Sci U S A, 2013. 110(3): p. 972-7.

17. Zhu, P., et al., Metformin selectively targets tumor-initiating cells in ErbB2overexpressing breast cancer models. Cancer Prev Res (Phila), 2014. 7(2): p. 199-210.

18. Poff, A.M., et al., The ketogenic diet and hyperbaric oxygen therapy prolong survival in mice with systemic metastatic cancer. PLoS One, 2013. 8(6): p. e65522.

19. Lee, C. and V.D. Longo, Fasting vs dietary restriction in cellular protection and cancer treatment: from model organisms to patients. Oncogene, 2011. 30(30): p. 3305-16.

20. Buchakjian, M.R. and S. Kornbluth, The engine driving the ship: metabolic steering of cell proliferation and death. Nat Rev Mol Cell Biol, 2010. 11(10): p. 715-27.

21. Anastasiou, D., et al., Pyruvate kinase M2 activators promote tetramer formation and suppress tumorigenesis. Nat Chem Biol, 2012. 8(10): p. 839-47.

22. Kuo, W., J. Lin, and T.K. Tang, Human glucose-6-phosphate dehydrogenase (G6PD) gene transforms NIH $3 T 3$ cells and induces tumors in nude mice. Int J Cancer, 2000. 85(6): p. 857-64.

23. Cori, C.F. and G.T. Cori, The carbohydrate metabolism of tumors. I. The free sugar, lactic acid, and glycogen content of malignant tumors. J. Biol. Chem., 1925. 64 p. 11-22.

24. Terada, T., Pure Glycogen-Rich Clear Cell Adenocarcinoma of the Stomach. J Gastrointest Cancer, 2013.

25. Markopoulos, C., et al., Glycogen-rich clear cell carcinoma of the breast. World J Surg Oncol, 2008. 6: p. 44.

26. Govender, D., et al., Clear cell (glycogen-rich) gastric adenocarcinoma. Ann Diagn Pathol, 2004. 8(2): p. 69-73.

27. Son, H.J., et al., Glycogen-rich clear cell mammary malignant myoepithelioma. Breast, 2004. 13(6): p. 506-9.

28. Ros, S. and A. Schulze, Linking Glycogen and Senescence in Cancer Cells. Cell Metabolism, 2012. 16(6): p. 687-688.

29. Tsavachidou, D., et al., Glycogen metabolism provides nutritional support to renal cancer cells under conditions of stress and may serve as a marker of response to 
antiangiogenic therapy with bevacizumab. AACR Meeting Abstracts, 2010. 2010(1_Molecular_Diagnostics_Meeting): p. PR12-.

30. Iida, Y., et al., Hypoxia promotes glycogen synthesis and accumulation in human ovarian clear cell carcinoma. Int J Oncol, 2012. 40(6): p. 2122-30.

31. Pescador, N., et al., Hypoxia promotes glycogen accumulation through hypoxia inducible factor (HIF)-mediated induction of glycogen synthase 1. PLoS One, 2010. 5(3): p. e9644.

32. Pelletier, J., et al., Glycogen synthesis is induced in hypoxia by the hypoxia-inducible factor and promotes cancer cell survival. Frontiers in Oncology, 2012. 2.

33. Brahimi-Horn, M.C., G. Bellot, and J. Pouysségur, Hypoxia and energetic tumour metabolism. Current Opinion in Genetics \& Development, 2011. 21(1): p. 67-72.

34. Favaro, E., et al., Glucose Utilization via Glycogen Phosphorylase Sustains Proliferation and Prevents Premature Senescence in Cancer Cells. Cell Metabolism, 2012. 16(6): p. 751-764.

35. Lee, W.N., et al., Metabolic sensitivity of pancreatic tumour cell apoptosis to glycogen phosphorylase inhibitor treatment. Br J Cancer, 2004. 91(12): p. 2094-100.

36. Benito, J., et al., Pronounced hypoxia in models of murine and human leukemia: high efficacy of hypoxia-activated prodrug PR-104. PLoS One, 2011. 6(8): p. e23108.

37. Thing Mortensen, B., et al., Changing bone marrow micro-environment during development of acute myeloid leukaemia in rats. British Journal of Haematology, 1998. 102(2): p. 458-464.

38. el-Khatib, M., N.S. Radin, and J.A. Shayman, Glycosphingolipid synthesis and proliferation in a renal cell line grown in high glucose. American Journal of Physiology Renal Physiology, 1996. 270(3): p. F476-F484.

39. Zador, I.Z., et al., A role for glycosphingolipid accumulation in the renal hypertrophy of streptozotocin-induced diabetes mellitus. The Journal of Clinical Investigation, 1993. 91(3): p. 797-803.

40. Jope, R.S., C.J. Yuskaitis, and E. Beurel, Glycogen synthase kinase-3 (GSK3): inflammation, diseases, and therapeutics. Neurochem Res, 2007. 32(4-5): p. 577-95.

41. Leni, Z., G. Parakkal, and A. Arcaro, Emerging metabolic targets in the therapy of hematological malignancies. Biomed Res Int, 2013. 2013: p. 946206.

42. Marín-Hernández, A., et al., Modeling cancer glycolysis. Biochimica et Biophysica Acta (BBA) - Bioenergetics, 2011. 1807(6): p. 755-767.

43. Shanmugam, M., S.K. McBrayer, and S.T. Rosen, Targeting the Warburg effect in hematological malignancies: from PET to therapy. Curr Opin Oncol, 2009. 21(6): p. 5316. 
44. Partridge, A.H., H.J. Burstein, and E.P. Winer, Side Effects of Chemotherapy and Combined Chemohormonal Therapy in Women With Early-Stage Breast Cancer. JNCI Monographs, 2001. 2001(30): p. 135-142.

45. Marko, A.J., et al., Induction of Glucose Metabolism in Stimulated T Lymphocytes Is Regulated by Mitogen-Activated Protein Kinase Signaling. PLoS ONE, 2010. 5(11): p. e15425.

46. Igney, F.H. and P.H. Krammer, Immune escape of tumors: apoptosis resistance and tumor counterattack. Journal of Leukocyte Biology, 2002. 71(6): p. 907-920.

47. Ladisch, S., S. Kitada, and E.F. Hays, Gangliosides shed by tumor cells enhance tumor formation in mice. J Clin Invest, 1987. 79(6): p. 1879-82.

48. Ladisch, S., et al., Shedding and Immunoregulatory Activity of YAC-1 Lymphoma Cell Gangliosides. Cancer Research, 1983. 43(8): p. 3808-3813.

49. Li, R., et al., Structural characterization and in vivo immunosuppressive activity of neuroblastoma GD2. Glycoconj J, 1996. 13(3): p. 385-9.

50. Hakomori, S.-i., Tumor Malignancy Defined by Aberrant Glycosylation and Sphingo(glyco)lipid Metabolism. Cancer Research, 1996. 56(23): p. 5309-5318.

51. Vander Heiden, M.G., Targeting cancer metabolism: a therapeutic window opens. Nat Rev Drug Discov, 2011. 10(9): p. 671-84.

52. Yamaguchi, R. and G. Perkins, Finding a Panacea among Combination Cancer Therapies. Cancer Research, 2012. 72(1): p. 18-23.

53. Maschek, G., et al., 2-Deoxy-d-glucose Increases the Efficacy of Adriamycin and Paclitaxel in Human Osteosarcoma and Non-Small Cell Lung Cancers In Vivo. Cancer Research, 2004. 64(1): p. 31-34.

54. Aghaee, F., J. Pirayesh Islamian, and B. Baradaran, Enhanced radiosensitivity and chemosensitivity of breast cancer cells by 2-deoxy-d-glucose in combination therapy. $\mathrm{J}$ Breast Cancer, 2012. 15(2): p. 141-7.

55. Akers, L.J., et al., Targeting glycolysis in leukemia: a novel inhibitor 3-BrOP in combination with rapamycin. Leuk Res, 2011. 35(6): p. 814-20.

56. Gault, C., L. Obeid, and Y. Hannun, An Overview of Sphingolipid Metabolism: From Synthesis to Breakdown, in Sphingolipids as Signaling and Regulatory Molecules, C. Chalfant and M. Poeta, Editors. 2010, Springer New York. p. 1-23.

57. Tidhar, R., et al., Acyl chain specificity of ceramide synthases is determined within a region of 150 residues in the Tram-Lag-CLN8 (TLC) domain. J Biol Chem, 2012. 287(5): p. 3197-206.

58. Hartmann, D., et al., The equilibrium between long and very long chain ceramides is important for the fate of the cell and can be influenced by co-expression of CerS. Int J Biochem Cell Biol, 2013. 45(7): p. 1195-203. 
59. Grosch, S., S. Schiffmann, and G. Geisslinger, Chain length-specific properties of ceramides. Prog Lipid Res, 2012. 51(1): p. 50-62.

60. Mullen, T.D., Y.A. Hannun, and L.M. Obeid, Ceramide synthases at the centre of sphingolipid metabolism and biology. Biochem J, 2012. 441(3): p. 789-802.

61. Hannun, Y.A. and L.M. Obeid, Principles of bioactive lipid signalling: lessons from sphingolipids. Nat Rev Mol Cell Biol, 2008. 9(2): p. 139-50.

62. Haimovitz-Friedman, A., R.N. Kolesnick, and Z. Fuks, Ceramide signaling in apoptosis. British Medical Bulletin, 1997. 53(3): p. 539-553.

63. Obeid, L.M., et al., Programmed cell death induced by ceramide. Science, 1993. 259(5102): p. 1769-71.

64. Pettus, B.J., C.E. Chalfant, and Y.A. Hannun, Ceramide in apoptosis: an overview and current perspectives. Biochimica et Biophysica Acta (BBA) - Molecular and Cell Biology of Lipids, 2002. 1585(2-3): p. 114-125.

65. Gouaze-Andersson, V. and M.C. Cabot, Glycosphingolipids and drug resistance. Biochim Biophys Acta, 2006. 1758(12): p. 2096-103.

66. Chatterjee, S. and H. Wei, Roles of Glycosphingolipids in Cell Signaling: Adhesion, Migration, and Proliferation, in Methods in Enzymology, C.L. Yuan and T.L. Reiko, Editors. 2003, Academic Press. p. 300-312.

67. Cowart, L.A., Sphingolipids and metabolic disease. 2011, New York, NY [u.a.: Landes Bioscience [u.a.].

68. Hakomori, S.-i., The glycosynapse. Proceedings of the National Academy of Sciences, 2002. 99(1): p. 225-232.

69. Bremer, E.G., J. Schlessinger, and S. Hakomori, Ganglioside-mediated modulation of cell growth. Specific effects of GM3 on tyrosine phosphorylation of the epidermal growth factor receptor. Journal of Biological Chemistry, 1986. 261(5): p. 2434-2440.

70. Nojiri, H., M. Stroud, and S. Hakomori, A specific type of ganglioside as a modulator of insulin-dependent cell growth and insulin receptor tyrosine kinase activity. Possible association of ganglioside-induced inhibition of insulin receptor function and monocytic differentiation induction in HL-60 cells. Journal of Biological Chemistry, 1991. 266(7): p. 4531-7.

71. Yamamura, S., K. Handa, and S. Hakomori, A close association of GM3 with c-Src and Rho in GM3-enriched microdomains at the B16 melanoma cell surface membrane: a preliminary note. Biochem Biophys Res Commun, 1997. 236(1): p. 218-22.

72. Zhang, X. and F.L. Kiechle, Glycosphingolipids in Health and Disease. Annals of Clinical \& Laboratory Science, 2004. 34(1): p. 3-13. 
73. Zheng, M., et al., Regulatory role of GM3 ganglioside in alpha 5 beta 1 integrin receptor for fibronectin-mediated adhesion of FUA169 cells. Journal of Biological Chemistry, 1993. 268(3): p. 2217-22.

74. Nohara, K., F. Wang, and S. Spiegel, Glycosphingolipid composition of MDA-MB-231 and MCF-7 human breast cancer cell lines. Breast Cancer Research and Treatment, 1998. 48(2): p. 149-157.

75. Liang, Y.-J., et al., Differential expression profiles of glycosphingolipids in human breast cancer stem cells vs. cancer non-stem cells. Proceedings of the National Academy of Sciences, 2013. 110(13): p. 4968-4973.

76. Hakomori, S.-I. and Y. Zhang, Glycosphingolipid antigens and cancer therapy. Chemistry \& Biology, 1997. 4(2): p. 97-104.

77. Regina Todeschini, A. and S.-i. Hakomori, Functional role of glycosphingolipids and gangliosides in control of cell adhesion, motility, and growth, through glycosynaptic microdomains. Biochimica et Biophysica Acta (BBA) - General Subjects, 2008. 1780(3): p. 421-433.

78. Hakomori, S. and Y. Igarashi, Functional role of glycosphingolipids in cell recognition and signaling. J Biochem, 1995. 118(6): p. 1091-103.

79. Macher, B.A., W.M. Lee, and M.A. Westrick, Glycosphingolipids of normal and leukemic human leukocytes. Mol Cell Biochem, 1982. 47(2): p. 81-95.

80. Goff, B.A., et al., Gangliosides of human chronic lymphocytic leukemia and hairy cells. Eur J Biochem, 1983. 130(3): p. 553-7.

81. Anh-Tuan, N., et al., Gangliosides in human chronic lymphocytic leukaemia. Int J Cancer, 1985. 35(5): p. 643-6.

82. Pick, J., et al., Ganglioside composition in common acute lymphoblastic leukaemia. Haematologia (Budap), 1986. 19(1): p. 33-9.

83. O'Boyle, K.P., et al., Patterns of ganglioside expression in B cell neoplasms. Leuk Lymphoma, 1996. 21(3-4): p. 255-66.

84. Siddiqui, B., et al., Differential expression of ganglioside GD3 by human leukocytes and leukemia cells. Cancer Res, 1984. 44(11): p. 5262-5.

85. Gu, Y., et al., Silencing of GM3 synthase suppresses lung metastasis of murine breast cancer cells. Breast Cancer Research, 2008. 10(1): p. R1.

86. Schnaar RL, S.A., Stanley P. ।, Glycosphingolipids. Essentials of Glycobiology, ed. C.R. Varki A, Esko JD, et al. Vol. 2nd edition. 2009, Cold Spring Harbor (NY): Cold Spring Harbor Laboratory Press.

87. Siskind, L.J., et al., The BCL-2 Protein BAK Is Required for Long-chain Ceramide Generation during Apoptosis. Journal of Biological Chemistry, 2010. 285(16): p. 1181811826. 
88. Jean-Philippe, V. and R. Filippo, Role of the ceramide-signaling pathways in ionizing radiation-induced apoptosis. Oncogene, 2003. 22(54): p. 8645-8652.

89. Itoh, M., et al., Possible Role of Ceramide as an Indicator of Chemoresistance: Decrease of the Ceramide Content via Activation of Glucosylceramide Synthase and Sphingomyelin Synthase in Chemoresistant Leukemia. Clinical Cancer Research, 2003. 9(1): p. 415-423.

90. Liu, Y.Y., R.A. Hill, and Y.T. Li, Ceramide glycosylation catalyzed by glucosylceramide synthase and cancer drug resistance. Adv Cancer Res, 2013. 117: p. 59-89.

91. Gouaze-Andersson, V., et al., Ceramide and glucosylceramide upregulate expression of the multidrug resistance gene MDR1 in cancer cells. Biochim Biophys Acta, 2007. 1771(12): p. 1407-17.

92. Eckford, P.D. and F.J. Sharom, The reconstituted P-glycoprotein multidrug transporter is a flippase for glucosylceramide and other simple glycosphingolipids. Biochem J, 2005. 389(Pt 2): p. 517-26.

93. Lannert, H., et al., Functional Organization of the Golgi Apparatus in Glycosphingolipid Biosynthesis: LACTOSYLCERAMIDE AND SUBSEQUENT GLYCOSPHINGOLIPIDS ARE FORMED IN THE LUMEN OF THE LATE GOLGI. Journal of Biological Chemistry, 1998. 273(5): p. 2939-2946.

94. Gouazé, V., et al., Overexpression of glucosylceramide synthase and P-glycoprotein in cancer cells selected for resistance to natural product chemotherapy. Molecular Cancer Therapeutics, 2004. 3(5): p. 633-640.

95. Liu, Y.-Y., et al., Glucosylceramide synthase upregulates MDR1 expression in the regulation of cancer drug resistance through $\mathrm{cSrc}$ and beta-catenin signaling. Molecular Cancer, 2010. 9(1): p. 145.

96. Gouazé, V., et al., Glucosylceramide Synthase Blockade Down-Regulates P-Glycoprotein and Resensitizes Multidrug-Resistant Breast Cancer Cells to Anticancer Drugs. Cancer Research, 2005. 65(9): p. 3861-3867.

97. Pallis, M. and N. Russell, Strategies for overcoming p-glycoprotein-mediated drug resistance in acute myeloblastic leukaemia. Leukemia, 2004. 18(12): p. 1927-1930.

98. Chai, L., et al., The chemosensitizing activity of inhibitors of glucosylceramide synthase is mediated primarily through modulation of P-gp function. Int J Oncol, 2011. 38(3): p. 701-11.

99. Ogretmen, B. and Y.A. Hannun, Biologically active sphingolipids in cancer pathogenesis and treatment. Nat Rev Cancer, 2004. 4(8): p. 604-16.

100. Huang, W.C., et al., Glucosylceramide synthase inhibitor PDMP sensitizes chronic myeloid leukemia T315I mutant to Bcr-Abl inhibitor and cooperatively induces glycogen synthase kinase-3-regulated apoptosis. FASEB J, 2011. 25(10): p. 3661-73. 
101. Baran, Y., et al., Targeting glucosylceramide synthase sensitizes imatinib-resistant chronic myeloid leukemia cells via endogenous ceramide accumulation. J Cancer Res Clin Oncol, 2011. 137(10): p. 1535-44.

102. Morad, S.A. and M.C. Cabot, Ceramide-orchestrated signalling in cancer cells. Nat Rev Cancer, 2013. 13(1): p. 51-65.

103. Casson, L., et al., Inhibition of ceramide metabolism sensitizes human leukemia cells to inhibition of BCL2-like proteins. PLoS One, 2013. 8(1): p. e54525.

104. Liu, Y.-Y., et al., Oligonucleotides blocking glucosylceramide synthase expression selectively reverse drug resistance in cancer cells. Journal of Lipid Research, 2004. 45(5): p. 933-940.

105. Kartal, M., et al., Resveratrol triggers apoptosis through regulating ceramide metabolizing genes in human K562 chronic myeloid leukemia cells. Nutr Cancer, 2011. 63(4): p. 637-44.

106. Gerrard, G., et al., Glucosylceramide synthase inhibitors sensitise CLL cells to cytotoxic agents without reversing P-gp functional activity. Eur J Pharmacol, 2009. 609(1-3): p. 34-9.

107. Norris-Cervetto, E., et al., Inhibition of Glucosylceramide Synthase Does Not Reverse Drug Resistance in Cancer Cells. Journal of Biological Chemistry, 2004. 279(39): p. 40412-40418.

108. Patwardhan, G.A., et al., A New Mixed-Backbone Oligonucleotide against Glucosylceramide Synthase Sensitizes Multidrug-Resistant Tumors to Apoptosis. PLoS ONE, 2009. 4(9): p. e6938.

109. Grazide, S., et al., Cytoprotective effect of glucosylceramide synthase inhibition against daunorubicin-induced apoptosis in human leukemic cell lines. J Biol Chem, 2004. 279(18): p. 18256-61.

110. Peterschmitt, M.J., et al., Safety, tolerability, and pharmacokinetics of eliglustat tartrate (Genz-112638) after single doses, multiple doses, and food in healthy volunteers. J Clin Pharmacol, 2011. 51(5): p. 695-705.

111. Larsen, S.D., et al., Property-based design of a glucosylceramide synthase inhibitor that reduces glucosylceramide in the brain. J Lipid Res, 2012. 53(2): p. 282-91.

112. Needleman, P., J.V. Passonneau, and O.H. Lowry, Distribution of glucose and related metabolites in rat kidney. Vol. 215. 1968. 655-659.

113. Zhao, H., et al., Inhibiting Glycosphingolipid Synthesis Improves Glycemic Control and Insulin Sensitivity in Animal Models of Type 2 Diabetes. Diabetes, 2007. 56(5): p. 12101218.

114. Ji, L., et al., Effects of Endoglycoceramidase ord-Threo-1-phenyl-2-decanoylamino-3morpholino-1-propanol on Glucose Uptake, Glycolysis, and Mitochondrial Respiration in HL60 Cells. Archives of Biochemistry and Biophysics, 1998. 359(1): p. 107-114. 
115. Rathmell, J.C., et al., Akt-Directed Glucose Metabolism Can Prevent Bax Conformation Change and Promote Growth Factor-Independent Survival. Molecular and Cellular Biology, 2003. 23(20): p. 7315-7328.

116. Presley, J., et al., The End2 mutation in CHO cells slows the exit of transferrin receptors from the recycling compartment but bulk membrane recycling is unaffected. The Journal of Cell Biology, 1993. 122(6): p. 1231-1241.

117. Bielawski, J., et al., Simultaneous quantitative analysis of bioactive sphingolipids by high-performance liquid chromatography-tandem mass spectrometry. Methods, 2006. 39(2): p. 82-91.

118. Placzek, W.J., et al., A survey of the anti-apoptotic Bcl-2 subfamily expression in cancer types provides a platform to predict the efficacy of Bcl-2 antagonists in cancer therapy. Cell Death \& Disease, 2010. 1(5).

119. Pelicano, H., et al., Glycolysis inhibition for anticancer treatment. Oncogene, 2006. 25(34): p. 4633-4646.

120. Dwarakanath, B.S., Cytotoxicity, radiosensitization, and chemosensitization of tumor cells by 2-deoxy-D-glucose in vitro. J Cancer Res Ther, 2009. 5 Suppl 1: p. S27-31.

121. Macheda, M.L., S. Rogers, and J.D. Best, Molecular and cellular regulation of glucose transporter (GLUT) proteins in cancer. Journal of Cellular Physiology, 2005. 202(3): p. 654-662.

122. Pedersen, P.L., et al., Mitochondrial bound type II hexokinase: a key player in the growth and survival of many cancers and an ideal prospect for therapeutic intervention. Biochimica et Biophysica Acta (BBA) - Bioenergetics, 2002. 1555(1-3): p. 14-20.

123. Kroemer, G. and J. Pouyssegur, Tumor Cell Metabolism: Cancer's Achilles' Heel. Cancer Cell. 13(6): p. 472-482.

124. Spiro, M.J., Effect of diabetes on the sugar nucleotides in several tissues of the rat. Diabetologia, 1984. 26(1): p. 70-75.

125. Rebucci, M. and C. Michiels, Molecular aspects of cancer cell resistance to chemotherapy. Biochemical Pharmacology, 2013. 85(9): p. 1219-1226.

126. Dylla, S.J., et al., Colorectal Cancer Stem Cells Are Enriched in Xenogeneic Tumors Following Chemotherapy. PLoS ONE, 2008. 3(6): p. e2428.

127. Li, X., et al., Intrinsic Resistance of Tumorigenic Breast Cancer Cells to Chemotherapy. Journal of the National Cancer Institute, 2008. 100(9): p. 672-679.

128. Milone, M.R., et al., Acquired resistance to zoledronic acid and the parallel acquisition of an aggressive phenotype are mediated by p38-MAP kinase activation in prostate cancer cells. Cell Death \& Disease, 2013. 4(5).

129. Loges, S., et al., Silencing or Fueling Metastasis with VEGF Inhibitors: Antiangiogenesis Revisited. Cancer Cell. 15(3): p. 167-170. 
130. Lagadinou, E.D., et al., BCL-2 inhibition targets oxidative phosphorylation and selectively eradicates quiescent human leukemia stem cells. Cell Stem Cell, 2013. 12(3): p. 329-41.

131. Yamaguchi, R., et al., Efficient Elimination of Cancer Cells by Deoxyglucose-ABT263/737 Combination Therapy. PLoS ONE, 2011. 6(9): p. e24102.

132. Hakomori, S.-I., Functional Role of Glycosphingolipids in Tumor Progression. The Tohoku Journal of Experimental Medicine, 1992. 168(2): p. 211-222.

133. Nozue, M., et al., Melanoma antigen expression and metastatic ability of mutant B16 melanoma clones. Int J Cancer, 1988. 42(5): p. 734-8.

134. Yogeeswaran, G., B.S. Stein, and H. Sebastian, Altered Cell Surface Organization of Gangliosides and Sialylglycoproteins of Mouse Metastatic Melanoma Variant Lines Selected in Vivo for Enhanced Lung Implantation. Cancer Research, 1978. 38(5): p. 1336-1344.

135. Noguchi, M., et al., Endogenously produced ganglioside GM3 endows etoposide and doxorubicin resistance by up-regulating Bcl-2 expression in $3 L L$ Lewis lung carcinoma cells. Glycobiology, 2006. 16(7): p. 641-650.

136. Liu, Y., et al., GCS induces multidrug resistance by regulating apoptosis-related genes in K562/AO2 cell line. Cancer Chemother Pharmacol, 2010. 66(3): p. 433-9.

137. Fan, J., et al., Quantitative flux analysis reveals folate-dependent NADPH production. Nature, 2014. 510(7504): p. 298-302.

138. Kovacic, N., J. Müthing, and A. Marusic, Immunohistological and Flow Cytometric Analysis of Glycosphingolipid Expression in Mouse Lymphoid Tissues. Journal of Histochemistry \& Cytochemistry, 2000. 48(12): p. 1677-1689. 


\section{ABBREVIATIONS}

\begin{tabular}{|c|c|}
\hline 2-DG & 2-deoxyglucose \\
\hline $6-\mathrm{AN}$ & 6-aminonicatinomide \\
\hline FL5.12 HG & FL5.12 Hexokinase-I Glut-1 \\
\hline G6PD & Glucose-6-phosphate dehydrogenase \\
\hline GlcCer & Glucosylceramide \\
\hline GBA & $\beta$-Glucocerebrosidase \\
\hline GCS & Glucosylceramide synthase \\
\hline GLUT1 & Glucose transporter-1 \\
\hline GSL & Glycosphingolipid \\
\hline HPLC-MS/MS & High performance liquid chromatography-mass spectrometry \\
\hline HK1 & Hexokinase-I \\
\hline MDR & Multi-drug resistance \\
\hline MDR1 & Multidrug resistance gene \\
\hline P-gp & P-glycoprotein \\
\hline PPP & Pentose phosphate pathway \\
\hline PDMP & 1-phenyl-2-decanoylamino-3-morpholino-1-propanol \\
\hline PPMP & 1-phenyl-2-palmitoylamino-3-N-morpholine-1-propanol \\
\hline S1P & Sphingosine-1-phosphate \\
\hline SMase & Sphingomyelinase \\
\hline TCA & Tricarboxylic acid cycle \\
\hline
\end{tabular}




\title{
CURRICULUM VITAE
}

\author{
MORGAN STATHEM \\ 6007 Harvester Court | Burke, VA 22015 \\ +1 (571) 331-8914 | morgan.stathem@gmail.com
}

\section{EDUCATION}

$\begin{array}{ll}\text { 2013-2014 } & \text { University of Louisville School of Medicine (Transferred with Mentor) } \\ & \text { M.S., Pharmacology and Toxicology, Cancer Biology } \\ & \text { GPA: } 4.0 \\ \text { 2012-2013 } & \text { Medical University of South Carolina } \\ & \text { M.S., Drug Discovery and Biomedical Sciences } \\ & \text { GPA: } 3.97 \\ \text { 2007-2010 } & \text { University of Georgia (Athens) } \\ & \text { Bachelor of Science, Biological Sciences, magna cum laude } \\ & \text { Overall GPA: } 3.88 \text { Science GPA: } 3.95\end{array}$

\section{AWARDS AND HONORS}

2013

2013

2012

2009

2008

2008-2010

2007-2010
Travel Award, Southeastern Regional Lipid Conference IPIBS Fellow in Pharmacology and Toxicology, covering tuition, stipend, benefits GAANN Fellow in Lipidomics and Systems Biology Scholarship, covering tuition, stipend, benefits and travel stipend $(\$ 46,030.00)$

PAH Scholarship for Outstanding Achievement in Organic Chemistry College of Agricultural and Environmental Sciences Academic Scholarship Presidential Scholar (4.0 GPA, five semesters) Dean's List (>3.5 GPA, seven semesters)

\section{PROFESSIONAL EMPLOYMENT}

2011-2012 Paralegal, Clinical Technology Transfer Group, P.L.L.C., McLean, VA

- Reviewed and edited contracts for Phase I-IV clinical drug trials

- Point of contact for drafting and submitting consulting agreements for the firm

- Conducted market research for expansion of pharmaceutical industry clientele

2009-2010 Science Tutor, Athens Tutors, Athens, GA

- Tutored high school and college students in biology, general and organic chemistry

- Formulated a unique study plan and performance tracker to monitor the academic progress of each student

- Prepared applications for submission of pharmaceutical patents

- Performed extensive research for use in trademark litigation cases

- Consulted with domestic and international clients regarding case status and submission 


\section{CIVIC \& INTERNATIONAL EXPERIENCE}

Jan-Aug 2011 ALFMED Académie de Langues France Méditerranée, Perpignan, France Student, Au Pair, Teacher

May 2009 International Service Learning, Costa Rica and Panama Volunteer Student Physician

- Provided medical care to underserved populations in five rural communities

- Worked one-on-one with patients to diagnose illnesses, provide treatment plans, and prescribe adequate medication

2008-2009 St. Mary's Hospital, Athens, Georgia, USA

Student Volunteer

- Observed and assisted in post-operation medical procedures

- Maintained medical supplies and hydration for 20 post-surgical patients

\section{GRADUATE RESEARCH}

2012-Present GAANN Fellow in Lipidomics and Systems Biology, MUSC, Charleston, SC IPIBS Graduate Fellowship, University of Louisville School of Medicine Mentors: Leah Siskind, Ph.D. and Levi Beverly, Ph.D.

Research Project: establishing a link between glycolytic and sphingolipid metabolism as a target for the treatment of leukemia

Mentoring: responsible for the training of two CO-OP students 2-3 hours per day

2010

Undergraduate Honors Research in Nutritional Endocrinology, UGA, Athens, GA

Mentor: Silvia Giraudo, Ph.D.

Research project: the effect of a high fructose versus glucose diet on neural pathways involved in hunger and reward feeding

\section{PUBLICATIONS \& PRESENTATIONS}

Stathem et al. Bridging the Gap Between Leukemia Metabolism and Glycosphingolipids. Abstract for Poster Presentation. Southeastern Regional Lipid Conference, Nov 2013

Stathem et al. Elevated Glucose Metabolism and Glycosphingolipids in Leukemia: A Novel Mechanism. Abstract for Poster Presentation. International Ceramide Conference, Stony Brook University, Oct 2013

Stathem et al. Glycosphingolipid Metabolism and the Warburg Effect. Abstract for Poster Presentation. Research! Louisville, University of Louisville, Oct 2013

Stathem et al.Targeting Glycosphingolipid Metabolism for the Treatment of Leukemia. Abstract for Poster Presentation. Midwest Blood Club Symposium, Cincinnati Children's Hospital, Sep 2013

Stathem et al. Targeting Glycosphingolipid Metabolism for the Treatment of Leukemia. Abstract for Poster Presentation. Mechanisms and Models of Cancer Conference, The Salk Institute, Aug 2013

\section{LANGUAGES}

English - native language; French - proficient, CEFR B2

\section{HOBBIES}

Cooking; Hiking; Traveling; Tennis; Swimming 